\title{
SLC1A5 provides glutamine and asparagine necessary for bone development in mice
}

\author{
Deepika Sharma', Yilin Yu², Leyao Shen², Guo-Fang Zhang ${ }^{3,4}$, \\ Courtney M Karner ${ }^{1,2,5 *}$
}

${ }^{1}$ Department of Orthopaedic Surgery, Duke University School of Medicine, Durham, United States; ${ }^{2}$ Department of Internal Medicine, University of Texas Southwestern Medical Center, Dallas, United States; ${ }^{3}$ Sarah W. Stedman Nutrition and Metabolism Center \& Duke Molecular Physiology Institute, Duke University Medical Center, Durham, United States; ${ }^{4}$ Department of Medicine, Duke University School of Medicine, Durham, United States; ${ }^{5}$ Charles and Jane Pak Center for Mineral Metabolism and Clinical Research. University of Texas Southwestern Medical Center at Dallas, Dallas, United States

*For correspondence: courtney.karner@ utsouthwestern.edu

Competing interest: The authors declare that no competing interests exist.

Funding: See page 18

Received: 24 June 2021

Accepted: 12 October 2021

Published: 14 October 2021

Reviewing Editor: Ernestina Schipani, University of

Pennsylvania, United States

(c) Copyright Sharma et al. This article is distributed under the terms of the Creative Commons Attribution License, which permits unrestricted use and redistribution provided that the original author and source are credited.
Abstract Osteoblast differentiation is sequentially characterized by high rates of proliferation followed by increased protein and matrix synthesis, processes that require substantial amino acid acquisition and production. How osteoblasts obtain or maintain intracellular amino acid production is poorly understood. Here, we identify SLC1A5 as a critical amino acid transporter during bone development. Using a genetic and metabolomic approach, we show SLC1A5 acts cell autonomously to regulate protein synthesis and osteoblast differentiation. SLC1A5 provides both glutamine and asparagine which are essential for osteoblast differentiation. Mechanistically, glutamine and to a lesser extent asparagine support amino acid biosynthesis. Thus, osteoblasts depend on Slc1a5 to provide glutamine and asparagine, which are subsequently used to produce non-essential amino acids and support osteoblast differentiation and bone development.

\section{Introduction}

Osteoblasts are secretory cells responsible for producing and secreting the Collagen Type one rich extracellular bone matrix. Osteoblasts differentiate from mesenchymal progenitors in a wellcoordinated temporal sequence regulated by the transcription factors RUNX2 and OSX (encoded by Sp7) (Nakashima et al., 2002; Otto et al., 1997). Osteoblast progenitors are proliferative before undergoing terminal differentiation into postmitotic Collagen Type 1 (COL1A1) matrix producing osteoblasts (Quarles et al., 1992; Pardee et al., 1978; Tonna and Cronkite, 1961; Stein et al., 1990; Stein and Lian, 1993). Both proliferation and matrix production are biosynthetically demanding and burden osteoblasts with enhanced metabolic demands. For example, proliferation requires cells to increase nutrient and amino acid acquisition to generate the biomass necessary to duplicate cell mass for division. Likewise, matrix production places similar demands upon osteoblasts. Thus, bone formation is associated with increased synthetic demands due to osteoblast proliferation, differentiation, and bone matrix production (Guntur et al., 2014; Lee et al., 2017; Karner and Long, 2018; Riddle and Clemens, 2017).

These enhanced synthetic demands are predicted to require a constant supply of amino acids to sustain both proliferation and bone matrix production. Cells can obtain amino acids via uptake from the extracellular milieu or from de novo synthesis from glucose or other amino acids (Karner and 
Long, 2018; Flanagan and Nichols, 1964; Adamson and Ingbar, 1967; Finerman and Rosenberg, 1966; Yee, 1988; Palm and Thompson, 2017). In osteoblasts, amino acid consumption is known to be transcriptionally regulated (Elefteriou et al., 2006; Rached et al., 2010) and rapidly increases during differentiation and in response to osteoinductive signals (Karner et al., 2015; Shen et al., 2021; Yu et al., 2019; Hahn et al., 1969; Phang and Downing, 1973). Importantly, genetic mutations that limit amino acid uptake are associated with decreased proliferative capacity and reduced bone formation (Elefteriou et al., 2006; Rached et al., 2010; Hu et al., 2020). Despite this, little is known about how osteoblasts obtain the amino acids necessary to promote robust proliferation and bone matrix synthesis.

The regulation of amino acid supply is an important regulatory node that is frequently upregulated to support proliferation and biosynthesis in many pathological conditions (Garcia-Bermudez et al., 2018; Jones et al., 2019; Bhutia et al., 2015; Bröer et al., 2016). Amino acid uptake is controlled by a diverse array of membrane-bound transport proteins that transport amino acids into and out of the cell. Once inside the cell, amino acids have diverse fates. For example, amino acids may contribute directly to protein synthesis, facilitate signaling or be metabolized to generate ATP or other intermediate metabolites including other amino acids (DeBerardinis et al., 2007; Green et al., 2016; Wang et al., 2009; Karner and Long, 2017). How osteoblasts obtain or utilize amino acids is not well understood. We recently identified Alanine, Serine, Cysteine transporter 2 (ASCT2, denoted herein as SLC1A5, encoded by S/c1a5) as a potential regulator of amino acid supply in osteoblast progenitors (Shen et al., 2021; Hu et al., 2020). SLC1A5 is a $\mathrm{Na}^{+}$-dependent neutral amino acid exchanger that can transport glutamine, alanine, serine, asparagine, and threonine (Bröer et al., 1999; Scopelliti et al., 2018; Utsunomiya-Tate et al., 1996; Nakaya et al., 2014; Wu et al., 2021). In cancer cells, Slc1a5 upregulation is associated with metabolic reprograming and is necessary for increased proliferation and biosynthesis (Bröer et al., 2016; Liu et al., 2018; Ren et al., 2015; van Geldermalsen et al., 2016; Wang et al., 2014; Schulte et al., 2018; Hassanein et al., 2013). In comparison, little is known about the role of SLC1A5-dependent amino acid uptake during bone development.

Here, we define the role of amino acid uptake through Slc1a5 during bone development and homeostasis. Using a genetic and metabolic approach, we demonstrate Slc1a5 is required for osteoblast proliferation, differentiation and bone matrix production. Mechanistically, SLC1A5 provides glutamine and asparagine to maintain intracellular amino acid homeostasis in osteoblasts. Collectively, these data highlight the previously unknown role for Slc1a5 in osteoblasts regulating differentiation and bone development.

\section{Results}

\section{Slc1a5 is required for bone development}

We previously identified SIc1a5 as a potential regulator of proliferation and WNT induced osteoblast differentiation in stromal cells (Shen et al., 2021; Hu et al., 2020). To understand if Slc1a5 functions in osteoblasts, we first characterized Slc1a5 expression during osteoblast differentiation. Slc1a5 is highly expressed in both naive calvarial cells and bone marrow stromal cells and significantly increases during osteoblast differentiation (Figure 1A). To determine if Slc1a5 is required for osteoblast differentiation, we first utilized a CRISPR/Cas9 approach to knock out SIc1a5 in cultured calvarial cells (Figure 1-figure supplement 1A). Western blot analyses confirmed this approach effectively ablated SLC1A5 protein (Figure 1-figure supplement 1B). Slc1a5 targeting did not affect early osteoblast differentiation but did prevent the induction of the mature osteoblast genes Ibsp and Bglap and prevented matrix mineralization in primary calvarial cells (Figure 1B-C). To determine if Slc1a5-dependent amino acid uptake is important for osteoblast differentiation in vivo, we generated a conditional (floxed) Slc1a5 allele $\left(S / c 1 a 5^{f l}\right)$ using homologous recombination (Figure 1-figure supplement 1C). These mice were crossed with the Sp7tTA;tetOeGFP/Cre deleter mouse (denoted hereafter as Sp7Cre) that expresses GFP and Cre recombinase under the control of the Sp7 promoter to generate mice lacking Slc1a5 in committed osteoblast progenitors (Rodda and McMahon, 2006). Western blot analysis confirmed the specific ablation of SLC1A5 in bones isolated from Sp7Cre;Slc1a $5^{f / f l}$ mice (Figure 1-figure supplement 1D). Sp7Cre;Slc1a5 $5^{f /}$

fl mice were characterized by delayed endochondral and intramembranous ossification evident at both embryonic (E) day E14.5 and E15.5 (Figure 1D-E-). In addition to delayed mineralization, 


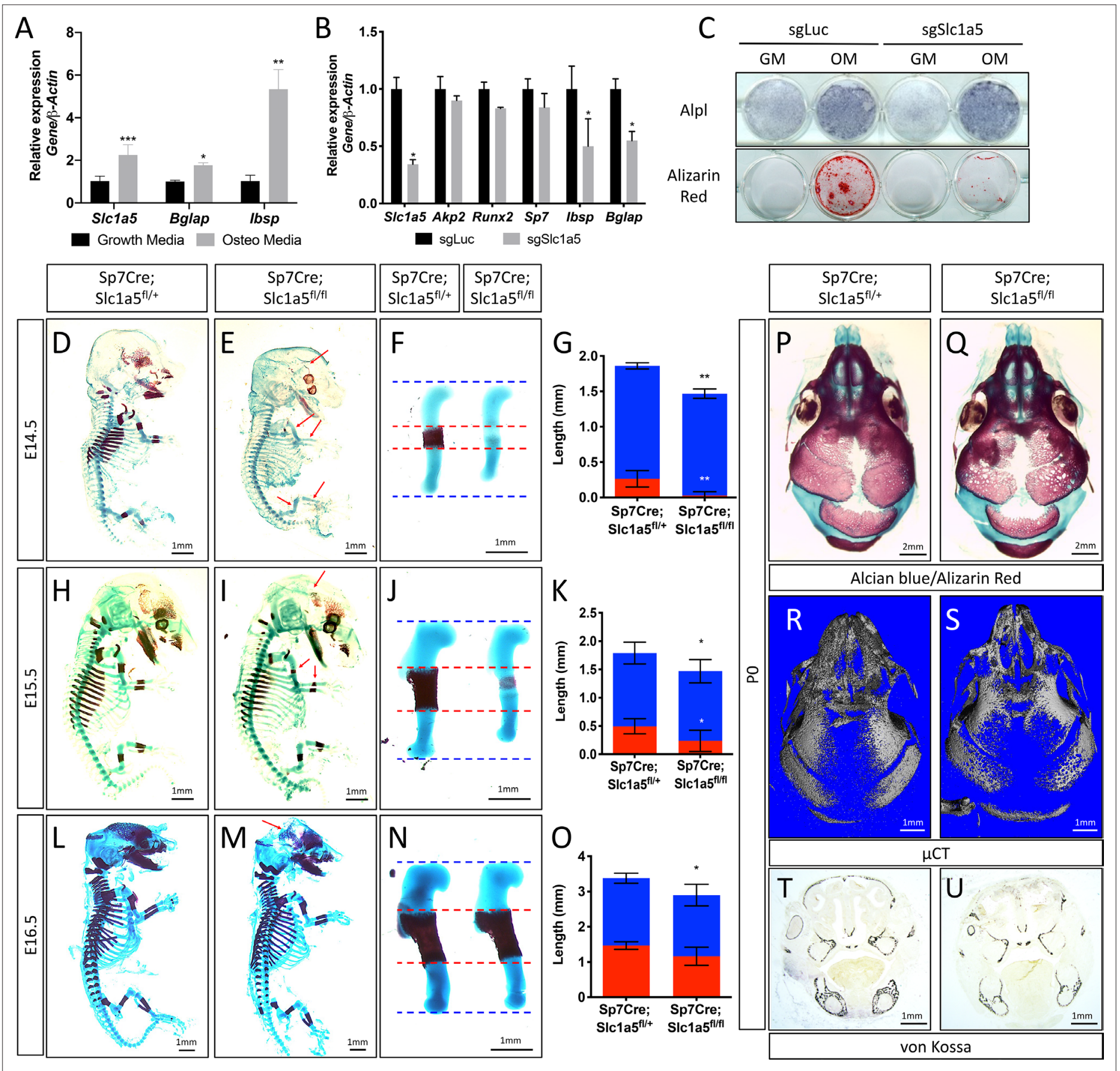

Figure 1. Slc1a5 is required for bone development in mice. (A) qRT-PCR analyses of gene expression in calvarial osteoblasts (cOB) cultured for 7 days in growth or osteogenic media. (B-C) qRT-PCR analyses (B) or functional assays (C) of the effect of S/c1a5 deletion on osteoblast differentiation in cOB cultured for 7 days in osteogenic media. (D-O) Skeletal preparations of Sp7Cre;Slc1a5 $5^{f / /}$ and Sp7Cre;Slc1a5 $5^{f / / t}$ mice at E14.5 ( $\left.n=5\right)$, E15.5 (N = 8) and E16.5 ( $(\mathbf{=}=5)$. Arrows denote reduced mineralization. Isolated humeri shown in $(\mathbf{F}),(\mathbf{J})$ and $(\mathbf{N})$. Blue dotted lines denotes the control overall humerus length. Red dotted lines denote control mineralized area. Images quantified in (G, K and $\mathbf{O})$. (P-S) A representative skeletal preparation (P-Q) or $(\mathbf{R}-\mathbf{S})$ Representative Micro-computed tomography $(\mu \mathrm{CT})(\mathrm{N}=6)$ used to quantify BV/TV(\%) and $(\mathbf{T}-\mathrm{U})$ von Kossa staining on Sp7Cre;Slc1a5 $5^{f /+}$ and Sp7Cre;Slc1a5/f/fl $(N=4)$ knockout mice at P0. Error bars depict SD. * $p \leq 0.05$, ** $p \leq 0.005$, *** $p \leq 0.0005$, *** $p \leq 0.00005$, by an unpaired two-tailed Student's t-test.

The online version of this article includes the following figure supplement(s) for figure 1 :

Source data 1. Contains numerical source data for Figure 1.

Figure supplement 1. Slc1a5 ablation decreases bone development.

Figure 1 continued on next page 
Figure 1 continued

Figure supplement 1-source data 1. Contains numerical and uncropped western blot source data for Figure 1-figure supplement 1.

Figure supplement 2. Skull phenotype at 2 months of age in Sp7Cre;Slc1a5fl/fl mice.

Sp7Cre;Slc1a $5^{f / f l}$ mice had reduced size of various skeletal elements (exemplified by the humerus,

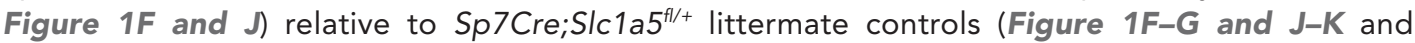
Figure 1-figure supplement 1E-L). By E16.5 the extent of mineralization was no longer significantly different although the overall length of individual skeletal elements was significantly different from Sp7Cre;Slc1a $5^{f / /+}$ littermate controls (Figure $1 \mathrm{~L}-\mathrm{O}$ and Figure 1-figure supplement 1M-P). At birth, neither matrix mineralization or nor element length were significantly different suggesting there is a transient delay in endochondral ossification (Figure 1-figure supplement 10-X). Conversely, Sp7Cre;Slc1a $5^{f / f l}$ mice are characterized by impaired intramembranous ossification at all stages evaluated (Figure 1D-E-, L-M and P-O and Figure 1-figure supplement 10-R). At birth, Sp7Cre;Slc1a $5^{f / f l}$ calvariae had increased porosity $\left(1.0 \pm 0.2\right.$ vs $2.3 \pm 0.2$ in Sp7Cre;Slc1a5 $5^{f /+}$

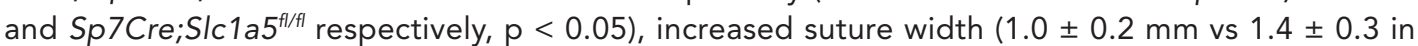
Sp7Cre;Slc1a5 $5^{f /+}$ and Sp7Cre;Slc1a5 $5^{f / f l}$ respectively, $\left.\mathrm{p}<0.05\right)$ and significantly less bone volume $\left(0.7 \% \pm 0.02 \%\right.$ vs $0.6 \pm 0.05 \%$ in Sp7Cre;Slc1a $5^{f / /+}$ and Sp7Cre;Slc1a5 $5^{f / f l}$ respectively, $\left.p<0.05\right)$ as measured by micro-computed tomography ( $\mu \mathrm{CT}$ ) (Figure 1). At 2-months of age, Sp7Cre;Slc1a5 $5^{f /}$ fl mice presented with less bone mass, increased suture width and altered suture morphology (Figure 1-figure supplement 2). Von Kossa staining of histological sections confirmed the reduction in mineralized bone matrix in newborn Sp7Cre;Slc1a $5^{f / f l}$ calvariae (Figure 1T-U). Thus, Slc1a5 expression in osteoprogenitors is essential for bone development.

\section{Slc1a5 is required for osteoblast differentiation and proliferation}

To determine how Slc1a5 regulates bone development, we first characterized the cellular effects of Slc1a5 ablation on osteoblasts. Because we observed a consistent skull phenotype at all stages and Sp7Cre is expressed in both osteoblasts and hypertrophic chondrocytes in the developing limb (Rodda and McMahon, 2006), we focused our analyses on the skull which is formed by intramembranous ossification and does not involve a cartilaginous intermediate (Ornitz and Marie, 2002). Von Kossa staining confirmed there was delayed mineralization in Sp7Cre;Slc1a5 $5^{f / f l}$ calvariae at E15.5 (Figure 2A-D). This was not due to changes in the number of osteoblast progenitors as we observed no significant difference in the number of $S p 7^{\text {GFP }}$ expressing osteoblast progenitors per bone area in Sp7Cre;Slc1a5 $5^{f / f l}$ mice compared to Sp7Cre;Slc1a5 $5^{f /+}$ wild type littermates $(75.3 \% \pm$ $11.6 \%$ vs $64.7 \pm 9.5 \%$ in Sp7Cre;Slc1a $5^{f /+}$ and Sp7Cre;Slc1a5 $5^{f / f}$ animals, respectively) (Figure 2E-F). However, we did observe a significant reduction in the proportion of Sp7 ${ }^{\text {GFP }}$ cells that were positive for proliferating cell nuclear antigen (PCNA) $\left(25.9 \% \pm 4.6 \%\right.$ vs $15.6 \pm 2.9 \%$ in Sp $7 \mathrm{Cre} ; \mathrm{Slc}_{\mathrm{C}} 5^{\mathrm{fl} /+}$ or Sp7Cre;Slc1a5 $5^{f / f l}$ respectively, $p<0.05$ ) (Figure 2G-J) suggesting Slc1a5 is required for proliferation of Sp7 expressing osteoblast progenitors. We next evaluated osteoblast differentiation using in situ hybridization. We did not observe significant differences in the expression of early osteoblast genes including alkaline phosphatase (Alpl, as determined by in situ staining) or Col1a1 (Figure $2 \mathrm{~K}-\mathrm{N}$ ). Conversely, Sp7Cre;Slc1a5 fl/fl animals had reduced expression of the osteoblast differentiation genes Spp1 and Ibsp at both E15.5 and postnatal (P) day 0 (P0) (Figure 2O-T and Figure 2-figure supplement 1A-B). Similarly, the mature osteoblast gene Bglap was highly

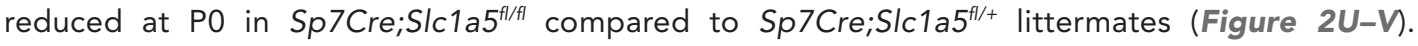
Consistent with these observations, primary calvarial cells isolated from Sp7Cre;Slc1a5 $5^{f / / f l}$ mice incorporated less EdU and were characterized by reduced osteoblast differentiation and matrix mineralization in vitro (Figure $2 \mathbf{W}-\mathbf{X}$ ). This is likely a direct effect of loss of Slc1a5 activity as acute SLC1A5 inhibition using GPNA reduced calvarial cell proliferation in vitro (Figure 2-figure supplement $1 \mathrm{~W}$ ). It is important to note we observed similar results in the developing long bones at both e15.5 and P0 (Figure 2-figure supplement 1C-V and Figure 2-figure supplement 2A-I). Similarly, 2 -month-old Sp7Cre;Slc1a $5^{f / / f l}$ mice had reduced osteoblast numbers (exemplified by OCN expression) and significantly less trabecular bone volume as measured by $\mu \mathrm{CT}$ in the distal femur compared to Sp7Cre;Slc1a5 $5^{f /+}$ wild -type littermate controls (Figure 2-figure supplement 


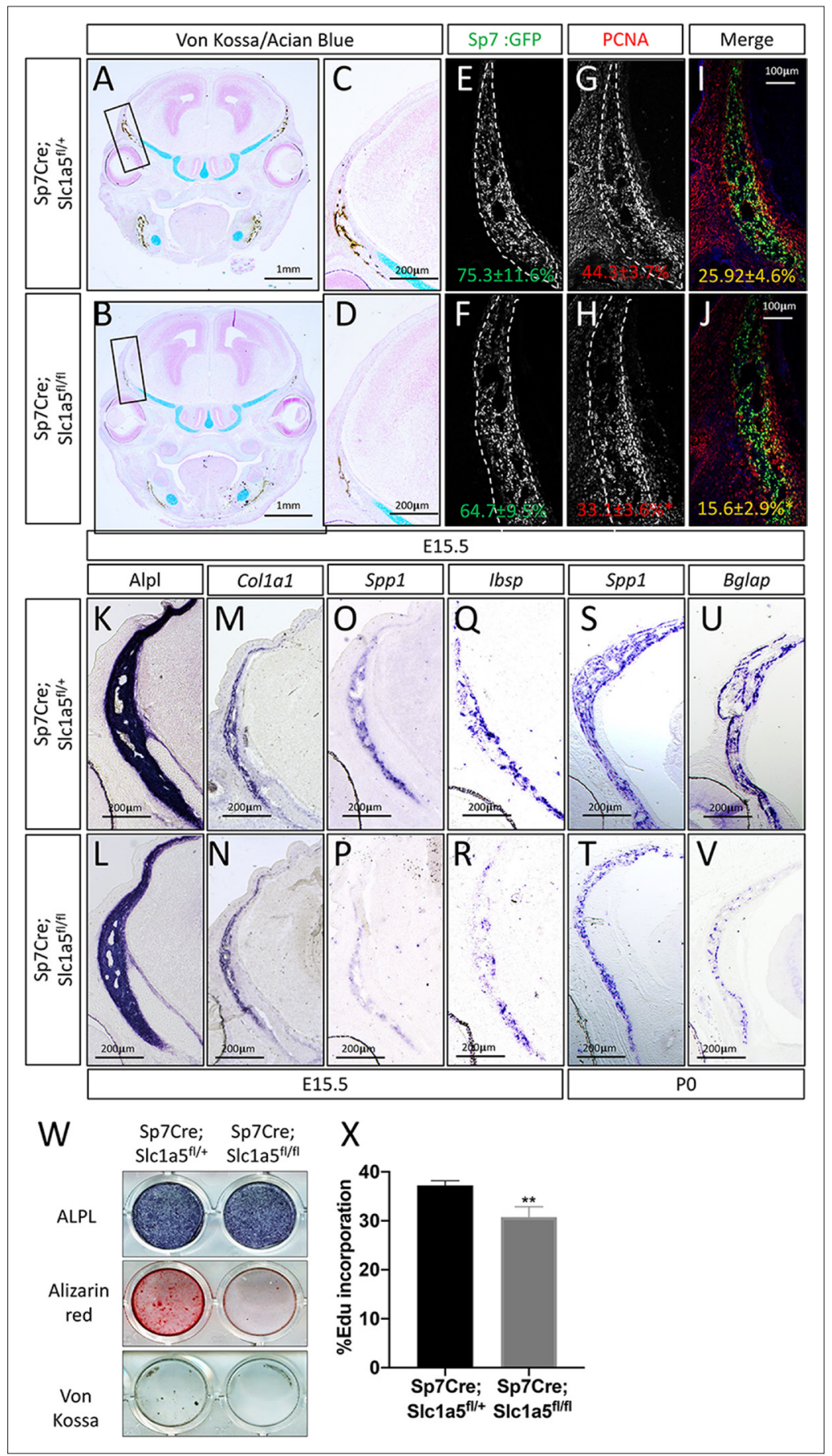

Figure 2. Slc1a5 is necessary for osteoblast proliferation and differentiation. (A-D) von Kossa/Alcian blue staining on Sp7Cre;Slc1af $f^{f /+}(\mathbf{A}, \mathbf{C})$ and Sp7Cre;Slc1a $5^{f / f}(\mathbf{B}, \mathbf{D})(\mathrm{N}=4)$ at E15.5. (E-J) Representative immunofluorescent staining for Proliferating Cell Nuclear Antigen (PCNA) used to quantify proliferation. Endogenous GFP from Sp $7^{\text {GFP }}$ shown in (G-H) used to quantify PCNA/GFP double positive cells. The numbers in each panel represent the percent GFP, PCNA or double positive cells per GFP positive bone area (dotted line). (K-V) Representative alkaline phosphatase (ALPL) staining (K-L) or In situ hybridization (M-V) for Col1a1, Spp1, Ibsp at E15.5 (N = 4) and Spp1, Bglap at PO (N = 3). (W) Functional assays of osteoblast differentiation in cOB isolated from Sp7Cre;Slc1a5 $5^{f /+}$ and Sp7Cre;Slc1a5 $5^{f / / t}$ mice. cultured for 14 days in osteogenic media. (X) Graphical depiction of EdU incorporation in cOB cells isolated from Sp7Cre;Slc1a5///+ and Sp7Cre;Slc1a5 $5^{f / / t}$ mice. Error bars depict SD. ${ }^{\star} p \leq 0.05,{ }^{\star *} p \leq 0.005$. by an unpaired two-tailed Student's t-test.

The online version of this article includes the following figure supplement(s) for figure 2:

Figure 2 continued on next page 
Figure 2 continued

Source data 1. Contains numerical source data for Figure 2.

Figure supplement 1. SLC1A5 is necessary for proliferation and endochondral ossification.

Figure supplement 1-source data 1. Contains numerical source data for Figure 2-figure supplement 1.

Figure supplement 2. Limb phenotypes at birth and 2 months in Sp7Cre;Slc1a5fl/fl mice.

Figure supplement 2-source data 1. Contains numerical source data for Figure 2—figure supplement 2.

$2 \mathrm{~J}-\mathrm{N})$. Collectively, these data indicate Slc1a5 acts cell-autonomously to regulate osteoprogenitor proliferation and osteoblast differentiation.

\section{Slc1a5 inhibition reduces protein synthesis in osteoblasts}

We next sought to understand how Slc1a5 regulates proliferation and differentiation. Because Slc1a5 encodes a neutral amino acid transporter, we hypothesized that Slc1a5 ablation would primarily affect protein synthesis. To test this hypothesis, we first evaluated protein synthesis directly by monitoring the incorporation of ${ }^{3} \mathrm{H}$-proline into protein. Slc1a5 targeting significantly reduced ${ }^{3} \mathrm{H}$-proline incorporation into both collagen and total protein (Figure 3-figure supplement 1A-B). Likewise, primary calvarial cells isolated from Sp7Cre;Slc1a $5^{f / f l}$ mice had significantly reduced protein and collagen synthesis rates in vitro (Figure $3 A-B$ ). These results indicate Slc1a5 is required for robust protein synthesis in osteoblasts. To test the validity of this conclusion, we evaluated the production of osteoblast proteins in vivo. Consistent with the in vitro data, Sp7Cre;Slc1a5 $5^{f / f l}$ mice were characterized by significantly less COL1A1 in both the calvariae and long bones at e15.5 and P0 (Figure 3C-H and Figure 2-figure supplement 1Q-R and Figure 3-figure supplement 1E-F). It is important to note, Col1a1 mRNA expression was not affected in these mice indicating Slc1a5 provides amino acids required for robust COL1A1 synthesis. Similarly, Sp7Cre;Slc1a $5^{f / f l}$ mice had a significant reduction in OSX protein expression as we observed a reduction in the proportion of OSX expressing cells despite no change in Sp7 ${ }^{G F P}$ expression (used as a proxy for Sp7) in Sp7Cre;Slc1a ff/fl calvariae (Figure 3I-N). Thus, Slc1a5 is essential for the synthesis of proteins like OSX to regulate terminal osteoblast differentiation and COL1A1 necessary for bone matrix production.

\section{Slc1a5 provides glutamine and asparagine to regulate amino acid homeostasis}

We next sought to define the molecular substrates of SLC1A5 in osteoblasts. First, we determined the effect of Slc1a5 knockout on downstream metabolites using mass spectrometry. Slc1a5 targeting significantly diminished the intracellular abundance of many amino acids including reported substrates of SLC1A5 (e.g. asparagine, glutamine, and alanine) as well as amino acids not known to be transported by SLC1A5 (e.g. glutamate, lysine, histidine, aspartate, glycine, and proline) (Figure 4A). Moreover, Slc1a5 deletion also reduced the abundance of select TCA cycle intermediates including fumarate, malate, citrate, and a-ketoglutarate (Figure 4-figure supplement 1A). Interestingly, the uptake of many of these amino acids was unaffected in Slc1a5-deficient cells as only glutamine and to a lesser extent asparagine uptake was diminished in Slc1a5 targeted calvarial cells (Figure 4B). Conversely, we observed a compensatory increase in the uptake of lysine in Slc1a5-deficient calvarial cells (Figure 4B). Similar results were obtained upon acute SLC1A5 inhibition indicating SLC1A5 transports glutamine and asparagine in osteoblasts (Figure 4-figure supplement 1B). Slc1a5-deficient cells had many cellular changes consistent with decreased amino acid concentrations. For example, Slc1a5 inhibition significantly increased EIF2a Ser51 phosphorylation, a marker of amino acid depletion (Figure 4C and Figure 4-figure supplement 1C). Additionally, we observed a significant reduction in mTORC1 activity, as both ribosomal protein S6 Ser240/244 phosphorylation and Eif4ebp1 Ser65 phosphorylation were significantly reduced in Slc1a5-deficient calvarial cells (Figure 4C). Interestingly, mTOR activation was not affected by acute SLC1A5 inhibition indicating decreased mTORC1 signaling may be a secondary effect of Slc1a5 deletion. Collectively, these data indicate SLC1A5 provides glutamine and asparagine to regulate intracellular amino acid homeostasis in osteoblast progenitors. 


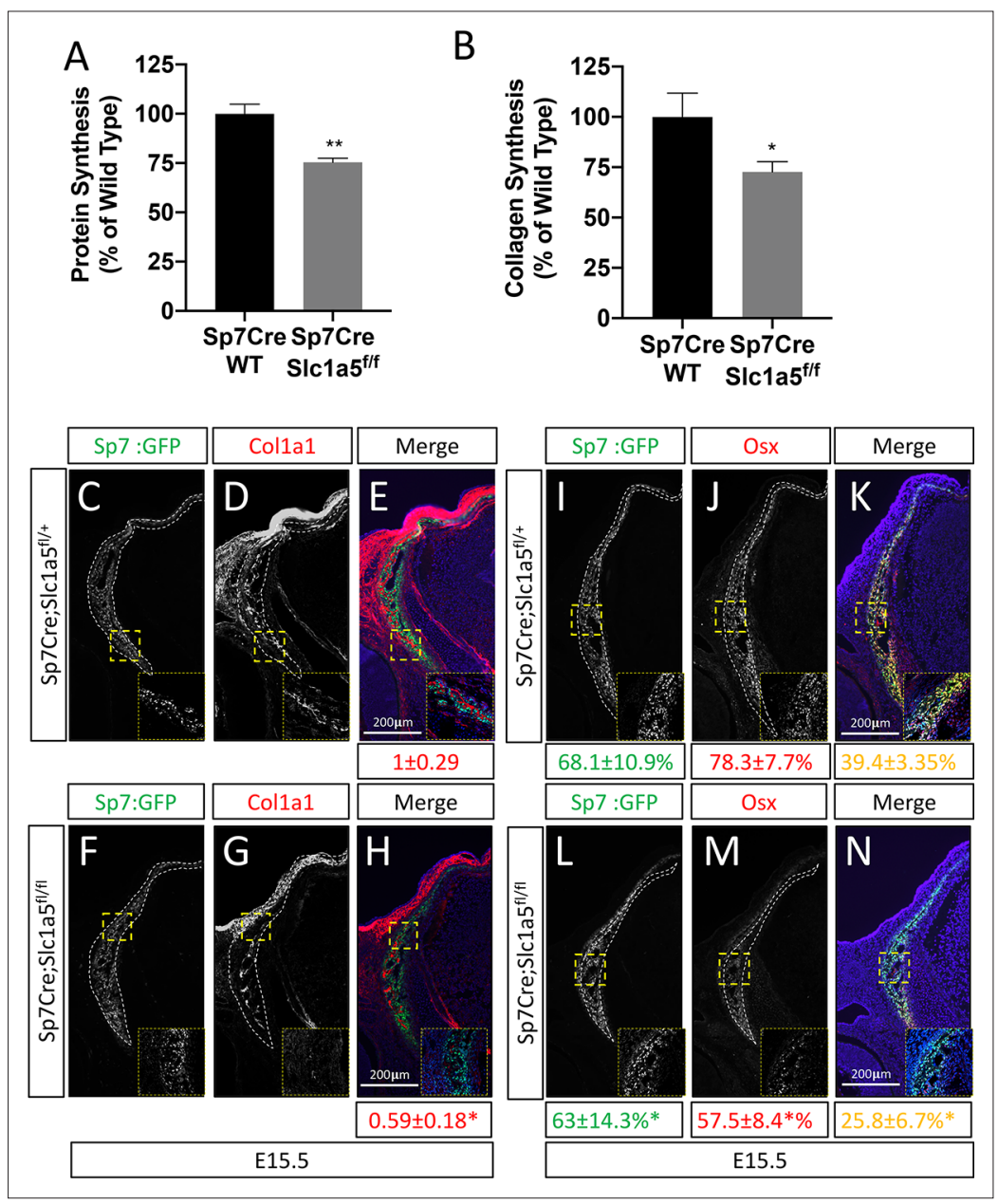

Figure 3. Slc1a5 is required for robust protein and matrix synthesis in osteoblasts. (A-B) Radiolabeled ${ }^{3} \mathrm{H}$-proline incorporation into total protein (A) or collagen (B) in cOB cells isolated from Sp7Cre;Slc1a $5^{f / /+}$ and Sp7Cre;Slc1a $5^{f / / f l}$ mice. (C-N) Representative immunofluorescent staining for Collagen Type 1 (COL1A1) (C-H) or OSX (I-N) at E15.5 in Sp7Cre;Slc1a $5^{f /+}(\mathbf{C}, \mathbf{D}, \mathbf{E}, \mathbf{I}, \mathbf{J}, \mathbf{K})$ and Sp7Cre;Slc1a $5^{f / / f l}(\mathbf{F}, \mathbf{G}, \mathbf{H}, \mathbf{L}, \mathbf{M}, \mathbf{N})$ mice. Endogenous GFP from Sp7 ${ }^{G F P}$ shown in $(\mathbf{C}, F, I, L)$. Col1a1 intensity was quantified in the GFP-positive region. Endogenous GFP from Sp7 $7^{\text {GFP }}$ shown in $(\mathbf{I}, \mathbf{L})$ was used to quantify OSX/GFP double positive cells. The numbers in each panel represent the percent GFP, OSX or double positive cells per GFP-positive bone area (dotted line). Inset images show $60 \mathrm{x}$ magnification of the indicated region. * $p \leq 0.05$, by an unpaired two-tailed Student's t-test.

The online version of this article includes the following figure supplement(s) for figure 3 :

Source data 1. Contains numerical source data for Figure 3.

Figure supplement 1. SLC1A5 is necessary for protein synthesis.

Figure supplement 1-source data 1. Contains numerical source data for Figure 3-figure supplement 1.

\section{Glutamine depletion mimics the effects of SIc1a5 deletion}

We next sought to understand the importance of both glutamine and asparagine for cellular function. To do this, we cultured naive calvarial cells in the absence of glutamine or in media treated with asparaginase to deplete asparagine. Depletion of either glutamine or asparagine from the media similarly inhibited the induction of terminal osteoblast genes Ibsp and Bglap and prevented matrix mineralization (Figures $1 \mathrm{~B}-\mathrm{C}$, and $5 \mathrm{~A}-\mathrm{B}$ ). While this was reminiscent of Slc1a5 ablation, it is important to note that glutamine withdrawal had a more profound effect on osteoblast differentiation compared to either asparagine depletion or Slc1a5 ablation. We next evaluated mTORC1 activity and EIF2a phosphorylation. Depletion of glutamine, but not asparagine, mimicked the effects of Slc1a5 targeting on both EIF2a Ser51 phosphorylation and mTORc1 activity (Figure 5C). Consistent with this, cells cultured 


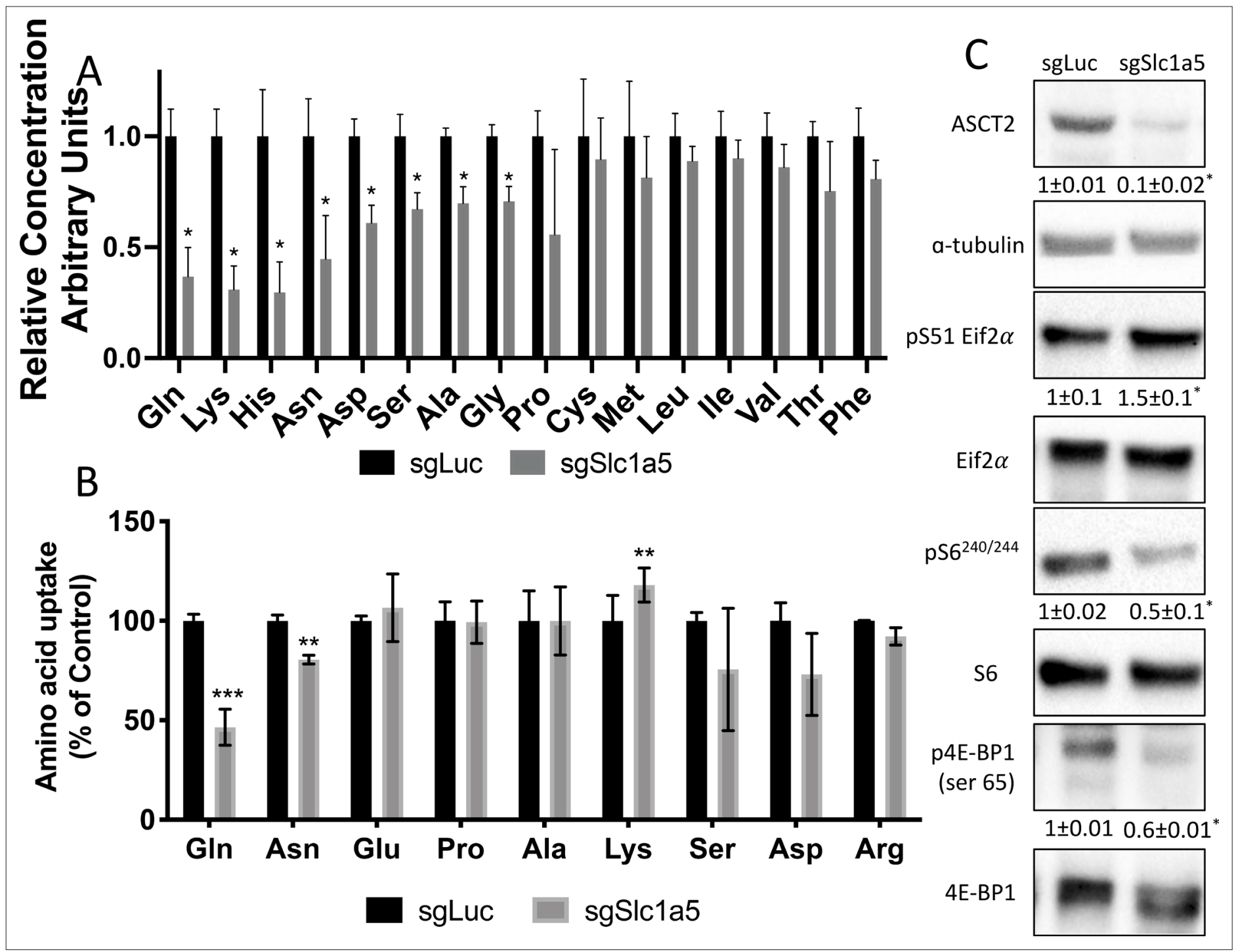

Figure 4. Slc1a5 provides glutamine and asparagine to maintain amino acid homeostasis. (A) Effect of Slc1a5 targeting on intracellular amino acid concentration measured by mass spectrometry.(B) Effect of Slc1a5 targeting on the uptake of indicated radiolabeled amino acids. (C) Western Blot analyses of the effect of Slc1a5 targeting on mTORC1 signaling and Eif2a phosphorylation. Phospho-proteins normalized to respective total protein. ASCT2 normalized to $\alpha$-tubulin. sgRNAs targeting luciferase were used as a negative control. Fold change \pm SD for sgSlc1a5 over sgLuc in three independent experiments. ${ }^{*} p \leq 0.05$ by an unpaired two-tailed Student's $t$-test.

The online version of this article includes the following figure supplement(s) for figure 4 :

Source data 1. Contains numerical and uncropped western blot source data for Figure 4.

Figure supplement 1. NEAA can partially rescue differentiation but not proliferation.

Figure supplement 1-source data 1. Contains numerical and uncropped western blot source data for Figure 4-figure supplement 1.

in the absence of glutamine had reduced COL1A1 expression and decreased proliferation like Slc1a5 deficient cells (Figure 5C-D). On the other hand, culturing cells in the absence of asparagine had no discernable effect on either pSer51 Eif2a, pSer240/244 S6rp, or COL1A1 expression and enhanced proliferation as determined by increased EdU incorporation (Figure 5C-D). Importantly, culturing cells in the absence of either glutamine or asparagine had no effect on cell viability (Figure 5E). From these data, we conclude SLC1A5 primarily provides glutamine to regulate amino acid homeostasis necessary for proliferation and osteoblast differentiation. Additionally, SLC1A5 provides asparagine which is essential for terminal osteoblast differentiation and matrix mineralization. 


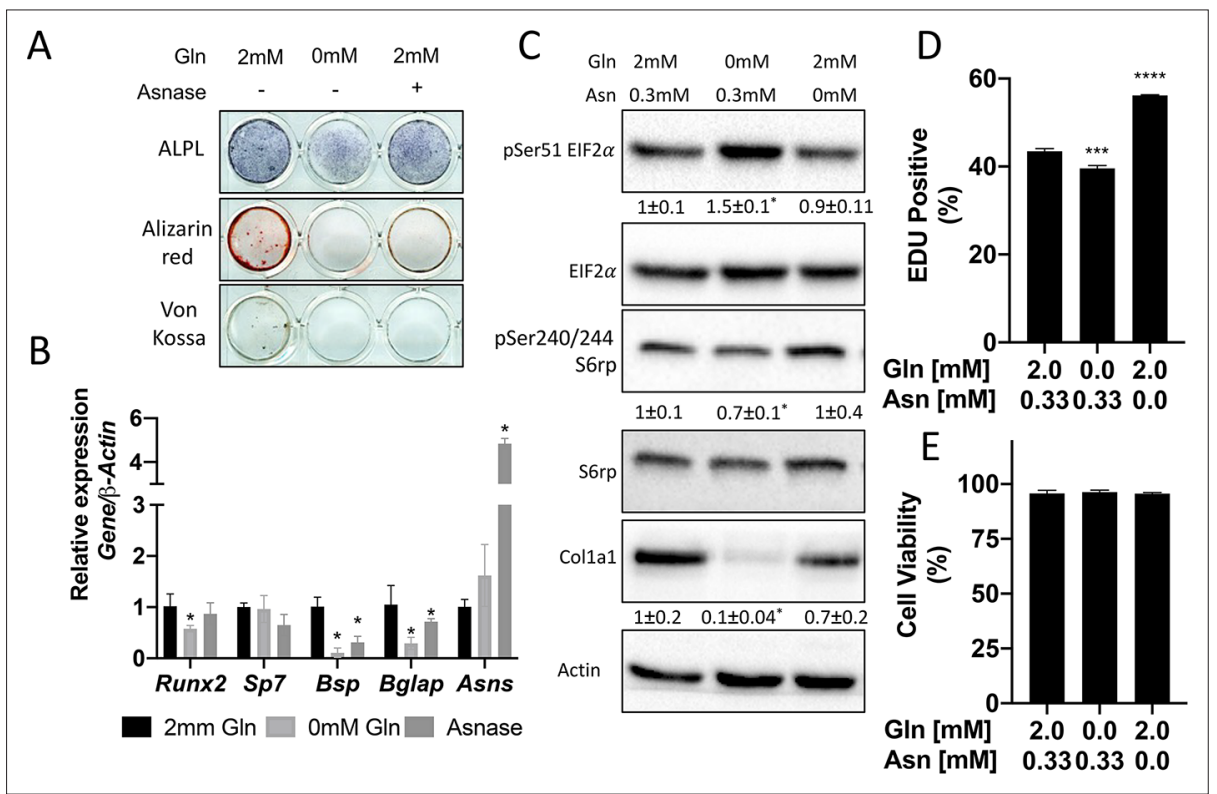

Figure 5. Glutamine and asparagine are required for osteoblast differentiation. (A-B) Functional assays (A) or qRTPCR analyses (B) of the effect of glutamine withdrawal or asparaginase treatment on $\mathrm{COB}$ cultured in osteogenic media for 14 days. (C) Western blot analyses of the effect of glutamine or asparagine withdrawal on mTORC1 signaling, Eif2a phosphorylation or COL1A1 expression. Phospho-proteins normalized to respective total protein. COL1A1 normalized to beta-actin. Fold change \pm SD for three independent experiments. ${ }^{*} \leq 0.05$ by an unpaired 2-tailed Student's t-test. (D-E) Effect of glutamine or asparagine withdrawal on EdU incorporation (D) or cell viability (E) as determined by Annexin $V$ staining.

The online version of this article includes the following figure supplement(s) for figure 5 :

Source data 1. Contains numerical and uncropped western blot source data for Figure $\mathbf{5}$.

\section{Glutamine and asparagine-dependent amino acid synthesis is essential for protein synthesis}

We next investigated how osteoblast utilize glutamine and asparagine. Since SLC1A5 ablation reduced intracellular amino acids, we hypothesized osteoblasts rely on glutamine and asparagine metabolism to maintain cellular amino acid pools. To test the validity of this hypothesis, we traced the relative contribution of glutamine or asparagine into amino acids directly. Consistent with previous reports, glutamine carbon contributes to all TCA cycle intermediates and was significantly enriched in several amino acids (e.g. glutamate, aspartate, alanine, and proline) found to be reduced in Slc1a5 targeted cells (Figure 6A, Figure 6-figure supplement 1A). Similarly, glutamine nitrogen was significantly enriched in glutamate, aspartate, alanine, serine, glycine and proline (Figure 6B). Consistent with the minor effects of asparagine withdrawal on markers of amino acid depletion, asparagine carbon was enriched only in aspartate, malate, fumarate, and citrate (Figure 6A, Figure 6-figure supplement 1A). On the other hand, asparagine nitrogen was enriched in aspartate, glutamate, proline, serine, and alanine (Figure 6A-B). Thus, glutamine contributes both carbon and nitrogen for amino acid biosynthesis whereas asparagine carbon is used only for aspartate biosynthesis while asparagine nitrogen is used in transamination reactions. Importantly, the amino acids derived from either glutamine carbon (e.g. Glu, Ala, Asp, Pro) and nitrogen (e.g. Glu, Ala, Asp, Ser, Gly and Pro) and asparagine carbon (e.g. Asp) and nitrogen (e.g. Asp, Pro, Ala, Ser) were significantly enriched in total protein (Figure $6 C-D$ ). Rescue experiments found NEAA did not rescue proliferation but could rescue the induction of terminal osteoblast marker genes like lbsp and to a lesser extent Bglap in Slc1a5deficient cells (Figure 4-figure supplement 1). These data indicate Slc1a5 provides glutamine and asparagine that are used for de novo synthesis of many amino acids (e.g. Glu, Asp, Ala, Ser, Gly, and Pro) that can be incorporated into nascent protein in osteoblasts.

Next, we sought to determine if glutamine-dependent amino acid synthesis was required for the high rate of protein synthesis in osteoblasts. We focused on glutamine because glutamine was more 


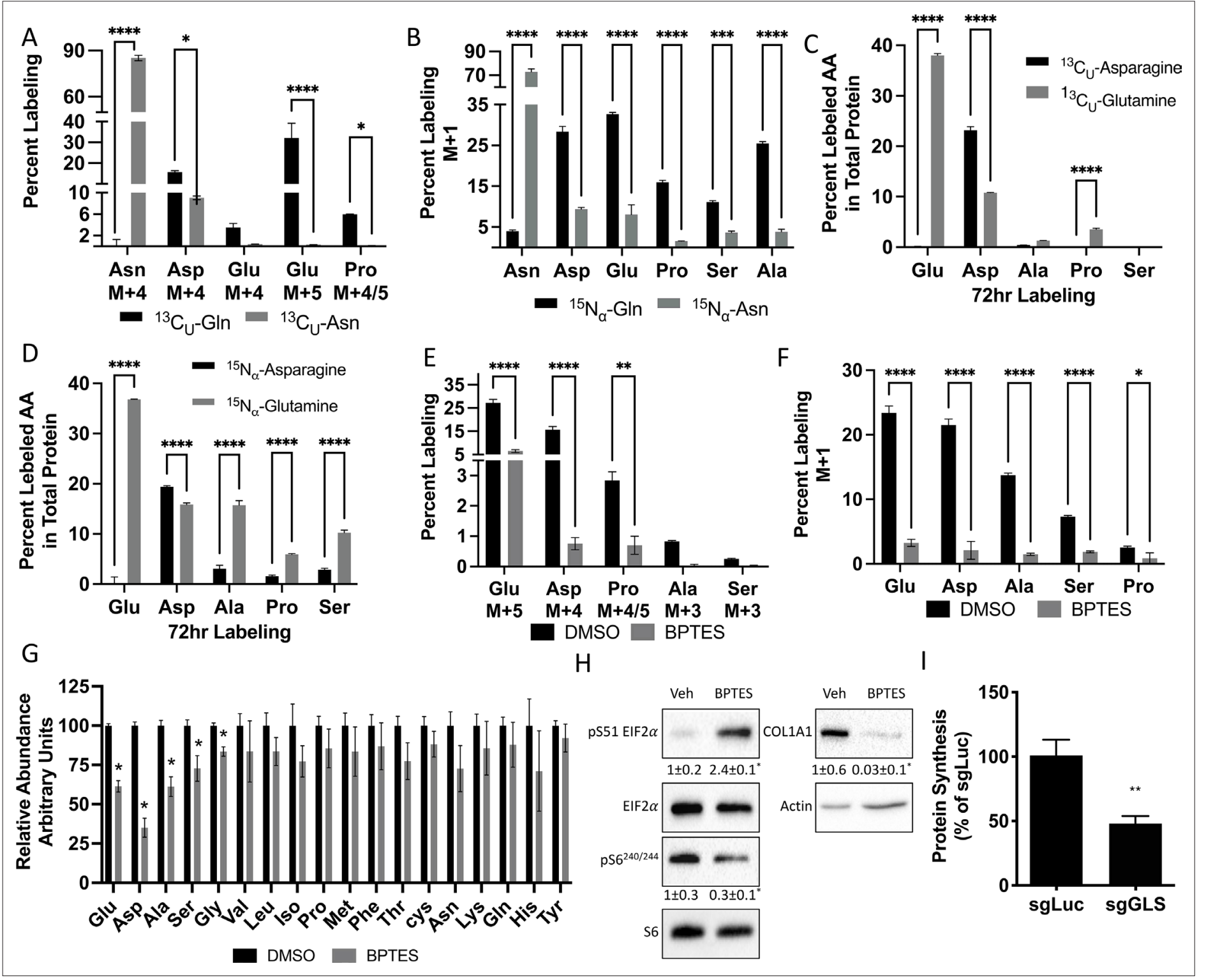

Figure 6. Glutamine and asparagine are utilized for de novo amino acid biosynthesis. (A-B) Fractional contribution of $\left[\mathrm{U}-{ }^{13} \mathrm{C}\right] \mathrm{glutamine}$ or $\left[\mathrm{U}-{ }^{13} \mathrm{C}\right]$ asparagine $(\mathbf{A})$ or $\left[\alpha-{ }^{15} \mathrm{~N}\right]$ glutamine or $[\alpha-15 \mathrm{~N}]$ asparagine $(\mathbf{B})$ to asparagine, aspartate, glutamate, proline, serine, and alanine. (C-D) Fractional contribution of $\left[\mathrm{U}-{ }^{13} \mathrm{C}\right]$ glutamine or $\left[U-{ }^{13} \mathrm{C}\right]$ asparagine $(\mathbf{C})$ or $[\alpha-15 \mathrm{~N}]$ glutamine or $[\alpha-15 \mathrm{~N}]$ asparagine $(\mathrm{D})$ to asparagine, aspartate, glutamate, proline, serine, and alanine in total protein. (E-F) Effect of BPTES treatment on the fractional contribution of $\left[U-{ }^{13} \mathrm{C}\right] \mathrm{glutamine}(\mathrm{E})$ or $[\alpha-15 \mathrm{~N}] \mathrm{glutamine}(\mathbf{F})$ to amino acids. ${ }^{*} p \leq 0.05,{ }^{\star \star} p \leq 0.005,{ }^{\star \star \star} p \leq 0.0005,{ }^{* \star \star} p \leq 0.00005$ by ordinary one-way ANOVA with Tukey's multiple comparisons. (G) Effect of GLS inhibition on intracellular amino acid concentration measured by mass spectrometry. ${ }^{*} p \leq 0.05$, multiple unpaired t-tests. Error bars depict $\mathrm{SD}$. (H) Western blot analyses of the effects of BPTES treatment on mTORC1 signaling, Eif2a phosphorylation and COL1A1 expression. Phospho-proteins normalized to respective total protein. COL1A1 normalized to beta-actin. Fold change \pm SD for three independent experiments. * $p \leq 0.05$ by an unpaired two-tailed Student's t-test. (I) Effect of GLS inhibition on protein synthesis as determined by the rate of ${ }^{3} \mathrm{H}$ Proline incorporation into total protein. ${ }^{*} p \leq 0.05$ by an unpaired two-tailed Student's $t$-test. Error bars depict SD.

The online version of this article includes the following figure supplement(s) for figure 6 :

Source data 1. Contains numerical and uncropped western blot source data for Figure 6.

Figure supplement 1 Inhibiting glutamine metabolism recapitulates molecular effects of SLC1A5 ablation.

Figure supplement 1-source data 1. Contains numerical and uncropped western blot source data for Figure 6-figure supplement 1. 
widely used for amino acid synthesis, and glutamine withdrawal more completely phenocopied the cellular effects of Slc1a5 targeting. To do this, we inhibited the enzyme glutaminase (GLS) which catalyzes the first rate-limiting step in glutamine metabolism. GLS inhibition using BPTES resulted in cellular effects similar to Slc1a5 ablation. GLS inhibition significantly reduced glutamine carbon and nitrogen contribution to amino acid synthesis and reduced the intracellular concentrations of glutamate, aspartate, alanine, serine, and glycine concentrations (Figure 6E-G). Consistent with reduced amino acid concentrations, GLS inhibition increased the presence of uncharged Glu, Asp, and Pro tRNA without affecting either Gln or Val tRNA charging (Figure 6-figure supplement 1D). Finally, GLS inhibition induced elF2 $\alpha$ Ser51 phosphorylation and reduced S6 Ser240/244 phosphorylation (Figure 6H). Consistent with these molecular changes, GLS inhibition significantly reduced EdU incorporation and COL1A1 expression (Figure 6H-I). Importantly, Gls targeting reduced overall protein synthesis like Slc1a5 targeting (Figure 6I, Figure 6-figure supplement 1E-G). These data highlight the importance of de novo amino acid synthesis to maintain amino acid homeostasis and promote proliferation and protein synthesis in osteoblasts.

\section{Discussion}

Here, we present data demonstrating that SLC1A5 is a critical regulator of osteoblast proliferation, differentiation and bone formation. Osteoblasts increase Slc1a5 expression as they undergo differentiation and increase bone matrix production. Genetically inhibiting SLC1A5 activity in preosteoblasts results in delayed endochondral and intramembranous ossification. Delayed bone development is the result of decreased osteoprogenitor proliferation as well as a reduction in overall osteoblast differentiation. Slc1a5 deficient osteoblasts have reduced protein synthetic activity which manifests in reduced OSX and COL1A1 protein expression. COL1A1 is the major organic component of bone matrix and OSX is required for terminal osteoblast differentiation (Nakashima et al., 2002). Mechanistically, SLC1A5 primarily provides glutamine and to a lesser extent asparagine in osteoblasts.

Glutamine is an essential nutrient in osteoblasts. We and others have shown that glutamine metabolism contribute to many downstream metabolites in osteoblasts including $\alpha K G$, non-essential amino acids (NEAA) and the tripeptide antioxidant glutathione (Karner et al., 2015; Yu et al., 2019; Stegen et al., 2021). These different studies have demonstrated these glutamine derived metabolites regulate distinct processes during osteoblast differentiation. For example, $\alpha K G$ is essential for skeletal stem cell proliferation, GSH regulates osteoblast viability while NEAA are important for differentiation (Yu et al., 2019; Stegen et al., 2021). We have extended these previous findings by identifying SLC1A5 as the primary glutamine transporter in osteoblasts. SLC1A5 is responsible for the majority of glutamine uptake importing $53.5 \%$ of glutamine in osteoblasts. In addition, Slc1a5 is a minor contributor to asparagine uptake importing only $19.5 \%$ of asparagine in osteoblasts (Figure 4 B). Consistent with our own and others previous reports, we found glutamine is a critical nutrient at all stages of osteoblast differentiation whereas asparagine is more important for terminal osteoblast differentiation. To our knowledge, this represents the first demonstration of the necessity of asparagine for osteoblast differentiation. Although, osteoblasts likely rely heavily on other transporters in addition to SLC1A5 to provide asparagine during differentiation.

Osteoblasts increase SLC1A5 expression to supply glutamine and asparagine which are used to maintain amino acid homeostasis. Interestingly, glutamine was more widely used for NEAA biosynthesis as our tracing experiments found glutamate, alanine, serine, aspartate, proline, and glycine were all synthesized from either glutamine carbon or nitrogen. Conversely, only aspartate was synthesized using asparagine carbon whereas Asp, Glu, Ala, and Ser were synthesized using asparagine nitrogen albeit at lower levels compared to glutamine (Figure 6A-B). It is important to note that while we focused our analyses on amino acid biosynthesis, our data does not preclude a role for glutamine and asparagine to support osteoblast proliferation or differentiation by providing other metabolites. Consistent with this, NEAA could not rescue proliferation in Slc1a5 deficient cells (Figure 4-figure supplement 1E). Moreover, the functional significance of asparagine derived amino acids in osteoblasts remains enigmatic. The effects of asparagine depletion on osteoblast differentiation may be due to direct effects on protein synthesis, reduction of select asparagine sensitive proteins or loss of an as yet undefined asparagine derived metabolite (e.g. nucleotides). Future studies into the role and downstream metabolism of asparagine in osteoblasts are warranted. 
It is interesting that glutamine and asparagine metabolism impinge upon aspartate biosynthesis in osteoblasts. Aspartate synthesis is critical for proliferation by providing both carbon and nitrogen for synthetic reactions (Birsoy et al., 2015; Sullivan et al., 2015). Thus, glutamine (and asparagine when glutamine is limiting) likely regulate proliferation in part by providing both carbon and nitrogen for aspartate biosynthesis (Pavlova et al., 2018). Aspartate synthesis likely occurs as part of the malate aspartate shuttle which is critical to regenerate oxidized $\mathrm{NAD}^{+}$to maintain high rates of glycolysis in osteoblasts (Lee et al., 2020). While we do not completely understand the metabolism of aspartate in osteoblasts, the aspartate derived from both glutamine and asparagine was enriched in total protein (Figure 6E). Interestingly, while glutamine contributed more to aspartate biosynthesis than asparagine, asparagine-derived aspartate was more highly enriched in total protein. This suggests disparate pools of aspartate exist in osteoblasts and that the metabolic fates for these glutamine- or asparagine-derived aspartate pools vary. For example, glutamine derived aspartate may contribute more to nucleotide biosynthesis to facilitate osteoblast proliferation whereas asparagine derived aspartate is used more for protein and matrix synthesis.

Proliferation is one of the initial stages of the osteoblast differentiation process. Proliferation is associated with increased demand for glucose and amino acids to support both nucleotide and NEAA biosynthesis required for cell division (Guntur et al., 2014; Karner and Long, 2018; Flanagan and Nichols, 1964; Hosios et al., 2016). To fulfil this need, proliferating cancer cells increase amino acid transporter expression to enhance amino acid supply (Bhutia et al., 2015; Liu et al., 2018; Hassanein et al., 2013; DeBerardinis et al., 2008; Jones et al., 2018; Kiyokawa et al., 1996; Krall et al., 2016). Here, we find that Slc1a5 provides glutamine and asparagine to osteoblasts, but that only glutamine is required for proliferation. This is consistent with recent reports that asparagine is important for proliferation only when glutamine is limited (Pavlova et al., 2018; Vander Heiden and DeBerardinis, 2017; Zhang et al., 2014). Glutamine is an essential nutrient in proliferating cells (Eagle, 1955), and recent studies found glutamine and its metabolism are critical for proliferation in osteoblast progenitor cells (Yu et al., 2019; Stegen et al., 2021). The precise mechanism by which SLC1A5 regulates proliferation remains unclear as amino acid supplementation was unable to rescue proliferation. This may be because NEAA uptake is inherently limited in osteoblasts resulting in the need for amino acid biosynthesis. Alternatively, glutamine catabolism provides amino acids and other intermediate metabolites (e.g. $\alpha-K G)$ to support proliferation. Consistent with this, we and others have shown that either $\alpha-K G$ or NEAA can rescue proliferation in GLS-deficient skeletal stem cells or osteoblasts respectively (Yu et al., 2019; Stegen et al., 2021).

During differentiation, osteoblasts increase their capacity for protein synthesis and secretion. Here, we find that Slc1a5 expression is required for robust protein synthesis in osteoblasts. This effect is likely regulated by multiple factors. First, Slc1a5 provides glutamine and asparagine that are likely directly incorporated into nascent protein. Second, our tracing data shows both glutamine and asparagine are used for de novo amino acid synthesis to support protein synthesis. Third, Slc1a5 provides glutamine to activate the mechanistic target of rapamycin complex 1 (mTORC1), an important regulator of both osteoblast proliferation and differentiation (Nicklin et al., 2009; Singha et al., 2008; Xian et al., 2012; Chen et al., 2014; Fitter et al., 2017). mTORC1 is tightly regulated by amino acid availability and functions to increase protein synthesis when amino acids are available. Consistent with this, Slc1a5-deficient osteoblasts had decreased mTORC1 activation and reduced protein synthesis (Figures 3A-B, and 4C). Finally, Slc1a5-deficient osteoblasts were characterized by robust activation of the integrated stress response (ISR). When amino acids are limiting, uncharged tRNA activates the kinase general control nonderepressible 2 (GCN2) which phosphorylates eukaryotic initiation factor 2 a (elF2a) to attenuate global protein synthesis (Zhang et al., 2002; Ye et al., 2010; Kroemer et al., 2010; Pakos-Zebrucka et al., 2016). These molecular changes in Slc1a5-deficient osteoblasts are primarily the result of reduced glutamine uptake as our drop out experiments found glutamine but not asparagine withdrawal reduced mTORC1 activation and increased ISR like Slc1a5 ablation (Figure 5C). Moreover, inhibiting glutamine catabolism similarly affected mTORC1 and ISR activation (Figure 6H). Thus, Slc1a5 provides glutamine used to maintain amino acid homeostasis to regulate protein synthesis directly and indirectly downstream of mTORC1 and GCN2-dependent ISR.

In summary, we have defined the necessity and the molecular substrates of Slc1a5 in osteoblasts. Our data indicates that SLC1A5 is the primary glutamine transporter in osteoblasts. In addition to glutamine, SLC1A5 acts cell autonomously in osteoblasts to provide asparagine, both of which are 
essential for osteoblast differentiation. These data highlight an elegant mechanism by which osteoblasts both directly obtain and synthesize the requisite amino acids to support osteoblast differentiation and bone formation.

\section{Key resources table}

\section{Materials and methods}

\begin{tabular}{|c|c|c|c|c|}
\hline $\begin{array}{l}\text { Reagent type (species) or } \\
\text { resource }\end{array}$ & Designation & Source or reference & Identifiers & Additional information \\
\hline $\begin{array}{l}\text { Genetic Reagent (M. } \\
\text { musculus) }\end{array}$ & C57Bl/6 J & Jackson Laboratory & RRID:IMSR_JAX:000664 & \\
\hline $\begin{array}{l}\text { Genetic Reagent (M. } \\
\text { musculus) }\end{array}$ & Rosa26Cas9 & Jackson Laboratory & RRID:IMSR_JAX:024858 & \\
\hline $\begin{array}{l}\text { Genetic Reagent (M. } \\
\text { musculus) }\end{array}$ & Rosa26Flpe & Jackson Laboratory & RRID:IMSR_JAX:003946 & \\
\hline $\begin{array}{l}\text { Genetic Reagent (M. } \\
\text { musculus) }\end{array}$ & Sp7tTA;tetOeGFP/Cre & PMID:16854976 & RRID:IMSR_JAX:006361 & \\
\hline $\begin{array}{l}\text { Genetic Reagent ( } M . \\
\text { musculus) }\end{array}$ & Slc1afflox & This paper & & $\begin{array}{l}\text { See Methods - Mouse } \\
\text { strains for more } \\
\text { information. }\end{array}$ \\
\hline Chemical compound, drug & Ascorbic acid & Sigma & Cat\#A4544 & \\
\hline Chemical compound, drug & $\beta$-glycerophosphate & Sigma & Cat\#G9422 & \\
\hline Chemical compound, drug & one-step NBT/BCIP solution & Thermofisher & Cat\#PI34042 & \\
\hline Chemical compound, drug & $\mathrm{L}-\left(2,3,4-{ }^{3} \mathrm{H}\right) \mathrm{Glutamine}$ & Perkin Elmer & Cat\#NET551250UC & \\
\hline Chemical compound, drug & $\mathrm{L}-\left({ }^{14} \mathrm{C}\right)$ Alanine & Perkin Elmer & Cat\#EC266E250UC & \\
\hline Chemical compound, drug & $\mathrm{L}-\left(2,3,{ }^{3} \mathrm{H}\right)$ Proline & Perkin Elmer & Cat\#NET483250UC & \\
\hline Chemical compound, drug & L-(2,3,- $\left.{ }^{3} \mathrm{H}\right)$ Aspartic acid & Perkin Elmer & Cat\#NET390V001MC & \\
\hline Chemical compound, drug & $\mathrm{L}-\left(4,5-{ }^{3} \mathrm{H}(\mathrm{N})\right)$ Lysine & Perkin Elmer & Cat\#NEC280E050UC & \\
\hline Chemical compound, drug & $\mathrm{L}-\left(2,3,{ }^{3} \mathrm{H}\right)$ Asparagine & $\begin{array}{l}\text { American Radiolabeled } \\
\text { Chemicals }\end{array}$ & Cat\#ART-0500-250 & \\
\hline Chemical compound, drug & {$\left[\mathrm{U}-{ }^{13} \mathrm{C}\right]$ glutamine, } & Sigma & Cat\#605,166 & $\begin{array}{l}\text { Used at } 2 \mathrm{mM} \text { final } \\
\text { concentration }\end{array}$ \\
\hline Chemical compound, drug & {$\left[\alpha-{ }^{15} \mathrm{~N}\right]$ glutamine } & Sigma & Cat\#486,809 & $\begin{array}{l}\text { Used at } 2 \mathrm{mM} \text { final } \\
\text { concentration }\end{array}$ \\
\hline Chemical compound, drug & {$\left[\mathrm{U}-{ }^{13} \mathrm{C}\right]$ Asparagine } & Sigma & Cat\#579,866 & $\begin{array}{l}\text { Used at } 0.33 \mathrm{mM} \text { final } \\
\text { concentration }\end{array}$ \\
\hline Chemical compound, drug & {$\left[\alpha-{ }^{15} N\right]$ Asparagine } & Sigma & Cat\#485,896 & $\begin{array}{l}\text { Used at } 0.33 \mathrm{mM} \text { final } \\
\text { concentration }\end{array}$ \\
\hline Chemical compound, drug & AP substrate BM purple & Roche & Cat\#11442074001 & \\
\hline Chemical compound, drug & ECL substrate & Biorad & Cat\#1705060 & \\
\hline Chemical compound, drug & super signal West Femto ECL. & Thermofisher & Cat\#1705060 & \\
\hline Antibody & Eif2 $\alpha$ (Rabbit monoclonal) & Cell Signaling & RRID:AB_10692650 & $(1: 1000)$ \\
\hline Antibody & pSer51 Eif2 $\alpha$ (Rabbit monoclonal) & Cell Signaling & RRID:AB_2096481 & $(1: 1000)$ \\
\hline Antibody & pSer240/244 S6rp(rabbit polyclonal) & Cell Signaling & RRID:AB_331682 & $(1: 1000)$ \\
\hline Antibody & S6rp (rabbit monoclonal) & Cell Signaling & RRID:AB_331355 & $(1: 1000)$ \\
\hline Antibody & $\alpha$-tubulin (rabbit monoclonal) & Cell Signaling & RRID:AB_2619646 & $(1: 1000)$ \\
\hline Antibody & $\alpha$-actin (rabbit polyclonal) & Cell Signaling & RRID:AB_330288 & $(1: 2000)$ \\
\hline Antibody & HRP goat anti-rabbit (goat polyclonal) & Cell Signaling & RRID:AB_2099233 & $(1: 2000)$ \\
\hline
\end{tabular}

Continued on next page 
Continued

\begin{tabular}{|c|c|c|c|c|}
\hline $\begin{array}{l}\text { Reagent type (species) or } \\
\text { resource }\end{array}$ & Designation & Source or reference & Identifiers & Additional information \\
\hline Antibody & HRP anti-mouse (horse polyclonal) & Cell Signaling & RRID:AB_330924 & $(1: 2000)$ \\
\hline Antibody & COL1A1 (mouse monoclonal) & Santa Cruz & RRID:AB_2797597 & $(1: 2000)$ WB $(1: 1000)$ IF \\
\hline Antibody & OSX (rabbit polyclonal) & Abcam & RRID:AB_2194492 & $(1: 1000)$ \\
\hline Antibody & PCNA (mouse monoclonal) & Cell Signaling & RRID:AB_2160343 & $(1: 500)$ \\
\hline Antibody & $\begin{array}{l}\text { goat anti mouse } 568 \text { (goat unknown } \\
\text { clonality) }\end{array}$ & Thermofisher & RRID:AB_141359 & $(1: 1000)$ \\
\hline Antibody & goat anti Rabbit 568 (goat polyclonal) & Thermofisher & RRID:AB_143157 & $(1: 1000)$ \\
\hline Commercial assay or kit & Iscript Reverse transcription kit & Biorad & Cat\#1708841 & \\
\hline Commercial assay or kit & SYBR green & Biorad & Cat\#1725275 & \\
\hline Commercial assay or kit & $\begin{array}{l}\text { Click-iT EdU Cell Proliferation Imaging } \\
\text { Kit }\end{array}$ & Invitrogen, & Cat\#C10337 & \\
\hline Commercial assay or kit & $\begin{array}{l}\text { Click-iT EdU Alexa Fluor } 488 \text { Flow } \\
\text { Cytometry Assay Kit }\end{array}$ & Invitrogen & Cat\#C10420 & \\
\hline Commercial assay or kit & Apoptosis Assay Kit (Cat\# 22837). & AAT BIO & Cat\# 22,837 & \\
\hline Chemical compound, drug & AP substrate BM purple & Roche & Cat\#11442074001 & \\
\hline Software Algorithm & Graphpad 6 & $\begin{array}{l}\text { https://www.graphpad. } \\
\text { com// }\end{array}$ & & \\
\hline
\end{tabular}

\section{Mouse strains}

C57BI/6 J (RRID:IMSR_JAX:000664), Rosa26Cas9 (RRID:1MSR_JAX:024858), Sp7tTA;tetOeGFP/Cre (RRID:IMSR_JAX:006361) (denoted in the text as Sp7Cre), and Rosa26Flpe (RRID:IMSR_JAX:003946) mouse strains were obtained from the Jackson Laboratory. The Slc1a $5^{\text {flox }}$ mouse strain was generated by the Duke Cancer Institute Transgenic Core facility. Briefly, LoxP sites flanking exon two and a frt PGK neo-cassette were inserted in to the endogenous Slc1a5 locus using homologous recombination (Fig. S1). The chimeric mice containing the targeting vector were then crossed to the Rosa26Flpe mouse to remove the neomycin cassette. All mice were housed at $23{ }^{\circ} \mathrm{C}$ on a $12 \mathrm{hr}$ light/dark cycle and maintained on PicoLab Rodent Diet 290 (Lab diet\#5053, St. Louis, MO). Timed pregnant females euthanized, and embryos were analyzed at E14.5, E15.5, E16.5, and P0. Sp7tTA;tetOeGFP/Cre mice expresses GFP and Cre recombinase under the control of the Sp7 promoter. We evaluated GFP as a proxy for Sp7 mRNA expression. The Sp7tTA;tetOeGFP/Cre mice have a partially penetrant bone phenotype. To control for this, in all genetic experiments, Sp7Cre;Slc1a $5^{f / f l}$ 'knockout' mice are always compared to Sp7Cre;Slc1a $5^{f /+}$ as 'wild type' littermate controls. All animal studies were approved by the animal studies committees at Duke University and the University of Texas Southwestern Medical Center at Dallas.

\section{Cell culture}

P3 pups were euthanized and the parietal and frontal bones were isolated according to standard protocols. The membranous tissue was removed, and the bones were washed and cleaned with PBS. The calvaria was chopped and four sequential 10 min digestions were performed with $1 \mathrm{mg} / \mathrm{ml}$ Collagenase $P$ in a shaking incubator at $37^{\circ} \mathrm{C}$. The first digestion was discarded, and the rest were combined. The digested calvarial cells were centrifuged and plated with $\alpha-M E M$ (GIBCO) supplemented with $15 \%$ FBS (Invitrogen). The cells were seeded at 50,000 cells $/ \mathrm{ml}$. To initiate osteoblast differentiation the growth media was replaced with $\alpha$-MEM with $10 \%$ FBS, $50 \mathrm{mg} / \mathrm{ml}$ ascorbic acid (Sigma) and $10 \mathrm{mM} \beta$-glycerophosphate (Sigma). RNA was isolated at day 7 after mineralization media was added. At day 14 , alizarin red and Von kossa staining was performed to visualize matrix mineralization. Alkaline phosphatase staining was performed using the one-step nitro-blue tetrazolium (NBT) and 5-brom o-4-chloro-3'-indolyphosphate p-toluidine salt (BCIP) solution (Thermofisher). For amino acid rescue experiments, cells were cultured for either $24 \mathrm{hr}$ (proliferation) or 7 days in $\alpha$-MEM supplemented 
Table 1. sgRNA sequences.

\begin{tabular}{ll} 
Slc1a5.g4 & ATTGATCTCCCGCTGGATACNGG \\
\hline Slc1a5.g1 & ACCCGTTGGAATCCTGTTCCNGG \\
\hline Slc1a5.g10 & AAAATCCCTATCGATTCCTGNGG \\
\hline Slc1a5.g17 & AGAAGAGGTCCCGAAAGCAGNGG \\
\hline Slc1a5.g31 & CCAGGAGCCCGTGGATGGCGNGG \\
\hline MS344.Gls.g5 & ATATAACTCATCGATGTGTGNGG \\
\hline MS344.Gls.g3 & GTGCTAAAAAGCAGTCTGGANGG \\
\hline MS345.Gls.g3 & CAAATTCAGTCCTGATTTGTNGG \\
\hline MS346.Gls.g14 & ATATTTCAGGGGTTTTACACNGG \\
\hline MS346.Gls.g1 & TGCAATTGCTGTTAATGACCNGG \\
\hline SP498.mCherry.g17 & CAAGTAGTCGGGGATGTCGGNGG \\
\hline SP498.mCherry.g19 & AGTAGTCGGGGATGTCGGCGNGG \\
\hline SP499.Luc.g3 & CAATTCTTTATGCCGGTGTTNGG \\
\hline SP399.Luc.g4 & GTGTTGGGCGCGTTATTTATNGG \\
\hline
\end{tabular}

to the indicated concentration with the following amino acids: $0.67 \mathrm{mM}$ glycine, $0.28 \mathrm{mM}$ alanine, $0.23 \mathrm{mM}$ aspartic acid, $0.2 \mathrm{mM}$ histidine, $0.24 \mathrm{mM}$ serine, $0.35 \mathrm{mM}$ proline, $0.4 \mathrm{mM}$ lysine, and $0.5 \mathrm{mM}$ arginine.

CRISPR/Cas9 targeting sgRNA vectors were purchased from the Genome Engineering and iPSC Center at Washington University School of Medicine. cOB were isolated from Rosa ${ }^{\text {Cas } 9}$ mice and were infected with five lentiviral delivered short guide RNAs targeting exons 4-6 of either Slc1a5 (sgSlc1a5) or Gls (sgGls) (Fig. S1 and S6). As a control cOB were infected with sgRNAs targeting the openreading frames of Luciferase and $m$ Cherry as a control (designated sgLuc in text and Fig.s). sgRNA sequences are listed in Table 1. To make virus, 293T cells were cotransfected with the lentiviral vector expressing short guide RNAs, pMD2.g and psPax2. After $48 \mathrm{hr}$ of transfection, the media containing the virus was collected and filtered through $0.45 \mu \mathrm{m}$ filter. cOB were cultured to $50 \%$ confluency and were infected for $24 \mathrm{hr}$ followed by recovery in regular media for another $24 \mathrm{hr}$.

\section{Uptake assays and proline incorporation assay}

Confluent primary cells were washed ones with PBS and two additionally washes with Krebs Ringer Hepes (KRH) $(120 \mathrm{mM} \mathrm{NaCl}, 5 \mathrm{mM} \mathrm{KCl}, 2 \mathrm{mM} \mathrm{CaCl}, 1 \mathrm{mM} \mathrm{MgCl}, 25 \mathrm{mM} \mathrm{NaHCO}, 5 \mathrm{mM}$ HEPES, $1 \mathrm{mM}$ D-Glucose, $\mathrm{pH}$ 8). Cells were then treated for $5 \mathrm{~min}$ with $\mathrm{KRH}$ containing $4 \mu \mathrm{Ci} / \mathrm{mL}$ of either $\mathrm{L}-\left(2,3,4-{ }^{3} \mathrm{H}\right)$ Glutamine, L- $\left({ }^{14} \mathrm{C}\right)$ Alanine, L- $\left(2,3,-{ }^{3} \mathrm{H}\right)$ Proline, L- $\left(2,3,-{ }^{3} \mathrm{H}\right)$ Aspartic acid, L- $\left(4,5-{ }^{3} \mathrm{H}(\mathrm{N})\right) \mathrm{Lysine}$, or $\mathrm{L}-\left(2,3,-{ }^{3} \mathrm{H}\right)$ Asparagine. After $5 \mathrm{~min}$, the uptake was terminated by washing the cells three times with ice cold $\mathrm{KRH}$. Cells were then scraped in $1 \mathrm{~mL}$ of $\mathrm{dH}_{2} \mathrm{O}$ and lysed by sonication for 1 min with 1 second pulses at $20 \%$ amplitude. The lysate was then centrifuged and mixed with $8 \mathrm{~mL}$ scintillation liquid. The counts per minute (CPM) were measured using a Beckman LS6500 scintillation counter. Proline incorporation assay was performed on confluent cells in a 12-well plate. The cells were washed ones with PBS and two additional washes with $\mathrm{KRH}$. The cells were incubated with $4 \mu \mathrm{Ci} / \mathrm{mL} \mathrm{L}\left(2,3,{ }^{3} \mathrm{H}\right)$ Proline in $\mathrm{KRH}$ at $37 \mathrm{C}$ for $3 \mathrm{hr}$. The uptake was terminated with three washes of cold $\mathrm{KRH}$, and the cells were scraped with $150 \mu \mathrm{I}$ RIPA. The lysates were then cleared and $90 \mu \mathrm{l}$ of the protein was precipitated with $10 \%$ tricholoroacetic acid (TCA). The pellet was washed three times with 5\%TCA and resuspended with $1 \mathrm{ml} 0.2 \mathrm{~N} \mathrm{NaOH}$. A total of $100 \mu \mathrm{l}$ of the lysate was saved to measure proline incorporation in total protein. The remaining lysate was separated in to two $400 \mu \mathrm{l}$ parts, to one-part $200 \mu \mathrm{l}$ of $60 \mu \mathrm{m}$ HEPES containing 10 units of collagenase was added and to the second part only HEPES was added. The lysates were incubated at $37 \mathrm{C}$ for $2 \mathrm{hr}$, followed by precipitation of undigested protein with $10 \%$ TCA. The supernatant was added to $8 \mathrm{ml}$ of scintillation liquid to measure proline incorporation in collagen using a Beckman LS6500 scintillation counter. 
Table 2. RT-PCR primer sequences.

\begin{tabular}{lll} 
Gene symbol & Forward & Reverse \\
\hline Slc1a5 & TGGAGATGAAAGACGTCCGC & CAGGCAGGCTGACACTGGAT \\
\hline -actin & AGATGTGGATCAGCAAGCAG & GCGCAAGTTAGGTTTTGTCA \\
\hline Akp2 & CCAACTCTTTTGTGCAGAGA & GGCTACATTGGTGTTGAGCTTTT \\
\hline Ibsp & CAGAGGAGGCAAGCGTCACT & GCTGTCTGGGTGCCAACACT \\
\hline Sp7 & CCTTCTCAAGCACCAATGG & AAGGGTGGGTAGTCATTTGCATA \\
\hline Bunx2 & CCAACCGAGTCATTTAAGGCT & GCTCACGTCGCTCATCTTG \\
\hline Asns & CAGCGGCCCTGAGTCTGA & GCCGGAGTCTGTTCACTACCTTA \\
\hline
\end{tabular}

\section{RT-PCR}

RNA was isolated using the Qiagen RNAeasy kit. 500 ng of RNA was reverse transcribed to cDNA using Iscript Reverse transcription kit (Biorad). The CDNA was diluted 1:10. qPCR reaction was setup using SYBR green (Biorad), $2 \mu \mathrm{l}$ of diluted cDNA and $0.1 \mu \mathrm{M}$ primers in technical and biological triplicates. $A B I$ Quantstudio three was used to run the $\mathrm{qPCR}$. The PCR cycle were $95^{\circ} \mathrm{C}$ for $3 \mathrm{~min}$ followed by 35 cycles of $95^{\circ} \mathrm{C}$ for $10 \mathrm{~s}$ and $60^{\circ} \mathrm{C}$ for $30 \mathrm{~s}$. Gene expression was normalized to ActB followed by calculating relative expression using the $2^{-(\Delta \Delta C t)}$ method. The list of primers is found in Table 2.

\section{Western blotting}

To isolate protein, cells were scraped, or bones were pulverized in RIPA lysis buffer ( $50 \mathrm{mM}$ Tris $(\mathrm{pH}$ 7.4), $15 \mathrm{mM} \mathrm{NaCl}, 0.5 \% \mathrm{NP}-40$ ) containing protease and phosphatase inhibitors (Roche). Protein concentration was measured using the BCA method and $10 \mu \mathrm{g}$ of the protein was run on $10 \%$ polyacrylamide gel. The protein was then transferred to a nitrocellulose membrane which was blocked for 1 hour at room temperature with $5 \%$ milk in TBST (TBS, $0.1 \%$ Tween20). The blots were then incubated with primary antibodies raised against ASCT2/SLC1A5 (RRID:AB_10621427, 1:1000), Eif2 $\alpha$ (RRID:AB_10692650), pSer51 Eif2 $\alpha$ (RRID:AB_2096481) pSer240/244 S6rp (RRID:AB_331682, 1:1000), S6rp (RRID:AB_331355, 1:1000), $\alpha$-tubulin (RRID: AB_2619646, 1:1000), or $\beta$-actin (RRID: AB_330288, 1:2000) overnight at 4 C. On day 2, the membranes were washed three times 5 min each with TBST and incubated with appropriate secondary antibody HRP goat anti-rabbit (RRID:AB_2099233) or HRP anti-mouse (RRID:AB_330924) in $5 \%$ milk in TBST for $1 \mathrm{hr}$ at room temperature. The membranes were again washed three times with TBST and developed using clarity ECL substrate (Biorad) or super signal West Femto ECL.

\section{EdU incorporation and annexin $\mathbf{V}$ assay}

5000 cells/well were seeded in a 96 well plate for 12-16 hr after which the cells were incubated with $10 \mu \mathrm{M}$ EdU (5-ethynyl-2'-deoxyuridine) for $6 \mathrm{hr}$. EdU incorporation was performed using the instructions provided in the Click-iT EdU Cell Proliferation Imaging Kit (Invitrogen, C10337). EdU incorporation was also analyzed using Click-iT EdU Alexa Fluor 488 Flow Cytometry Assay Kit (Invitrogen, C10420) after $24 \mathrm{hr}$ incubation with $10 \mu \mathrm{M}$ EdU. The cells were then trypsinized, permeabilized and stained as per kit instructions. Cell viability assay was performed using the Apoptosis Assay Kit (Cat\# 22837).

\section{Skeletal prep}

Timed pregnant females were euthanized, and pups were harvested at E14.5, E15.5, and P0. The embryos were skinned, eviscerated and dehydrated in $95 \%$ ethanol overnight. The mice were transferred to acetone for another night to dissolve fat tissue. After which, the tissue was stained with Alcian blue $8 \mathrm{GX}\left(0.03 \%, \mathrm{~m} / \mathrm{v}\right.$ in $70 \%$ ethanol) and Alizarin red $\mathrm{S}\left(0.005 \%, \mathrm{~m} / \mathrm{v}\right.$ in $\left.\mathrm{dH}_{2} \mathrm{O}\right)$ solution containing $10 \%$ acetic acid and $80 \%$ ethanol. The stained skeletons were cleared in $1 \% \mathrm{KOH}$ followed by a gradient of glycerol. 


\section{Histology, immunofluorescence, and in situ hybridization}

Limbs and skulls from E15.5, E16.5, and P0 were harvested skinned and fixed overnight in 4 \% PFA (paraformaldehyde). Limbs from E16.5 and P0 were decalcified in $14 \%$ EDTA overnight, followed by transferring them to $30 \%$ sucrose for frozen embedding in OCT and $70 \%$ ethanol for paraffin embedding. Paraffin embedded blocks were sectioned at $5 \mu \mathrm{M}$ thickness and utilized for Alcian blue and picro-sirius, von Kossa and alcian blue using standard protocols.

Immunofluorescence was performed on $10 \mu \mathrm{M}$ frozen sections brought to room temperature and incubated with $3 \% \mathrm{H}_{2} \mathrm{O}_{2}$ for $10 \mathrm{~min}$. The sections were then incubated with $1.5 \% \mathrm{goat}$ serum in PBST (PBS with $0.1 \%$ Tween20) at room temperature for $1 \mathrm{hr}$. The sections were then incubated overnight in primary antibodies COL1A1 (RRID:AB_638601,1:200), OSX (RRID:AB_2194492 1:500,), PCNA (RRID:AB_2160343,1:500) diluted in $1.5 \%$ goat serum in PBST. On day 2, the sections were washed three times with PBST for $5 \mathrm{~min}$ each and incubated with goat anti-mouse 568 (RRID:AB_141359, 1:1000) for COL1A1 and goat anti-Rabbit 568 (RRID:AB_143157, 1:1000) for OSX and PCNA for $30 \mathrm{~min}$ at room temperature. The sections were then mounted with DAPI and imaged. COL1A1 intensity was measured in the $S p 7^{G F P}$-positive region. OSX, Sp7 $7^{G F P}$ copositive cells were counted using Image J.

In situ hybridization was performed on $10 \mu \mathrm{M}$ frozen sections. The sections were fixed with $4 \%$ PFA for $10 \mathrm{~min}$ at room temperature followed by $10 \mathrm{~min}$ in acetylation solution $(1.3 \%$ triethanolamine, $0.175 \% \mathrm{HCl}, 0.375 \%$ acetic anhydride in $\mathrm{dH}_{2} \mathrm{O}$ ). The sections were then washed and incubated with hybridization buffer (50\% formamide (deionized), 5 X SSC, pH 4.5 (use citric acid to pH), $1 \%$ SDS, $50 \mu \mathrm{g} / \mathrm{mL}$ yeast tRNA, $50 \mu \mathrm{g} / \mathrm{mL}$ heparin) for $2 \mathrm{hr}$ in a humidified chamber. The excess hybridization buffer was removed and prewarmed probe diluted 1:10 was added to the slides, covered with parafilm and incubated at $60 \mathrm{C}$ overnight. The slides were immersed in 5 X SSC to remove the parafilm and washed twice with $0.2 \times$ SSC for $30 \mathrm{~min}$ at $60 \mathrm{C}$. After an additional wash at room temperature with $0.2 \times$ SSC the slides were transferred to NTT $(0.15 \mathrm{M} \mathrm{NaCl}, 0.1 \mathrm{M}$ tris-Cl pH 7.5, $0.1 \%$ tween 20) for $10 \mathrm{~min}$ at room temperature. The slides were blocked with blocking buffer $(5 \%$ heat inactivated sheep serum, $2 \%$ blocking reagent/NTT) for 2 hr, followed by incubation with anti-Dig AP antibody diluted at 1:4000 in the blocking buffer overnight at $4 \mathrm{C}$. On the third day, the slides were washed with NTT on rotator three times for $30 \mathrm{~min}$ each, followed by $35 \mathrm{~min}$ washes with NTTML $(0.15 \mathrm{M} \mathrm{NaCl}$, $0.1 \mathrm{M}$ tris $\mathrm{pH}$ 9.5, $50 \mathrm{mM} \mathrm{MgCl}_{2}, 2 \mathrm{mM}$ Levamisole, $0.1 \%$ tween 20). The slides were then incubated with prewarmed AP substrate BM purple (ROCHE) at $37 \mathrm{C}$ and monitored for desired staining. After staining was achieved the slides were rinsed in PBS 3 times for 5 min each. The slides were fixed in $0.2 \%$ glutaraldehyde in $4 \%$ PFA overnight, the slides were then mounted with glycergel and imaged.

\section{Micro computed tomography (uCT)}

Micro computed tomography $(\mu \mathrm{CT}$ ) (VivaCT80, Scanco Medical AG) was used for three-dimensional reconstruction and analysis of bone parameters. Calvariae were harvested from either newborn mice or 2-month-old mice. All muscle and extemporaneous tissue were removed and the isolated calvariae were washed in PBS, fixed overnight in 10\%NBF and dehydrated in $70 \%$ ethanol. The calvariae were immobilized in $2 \%$ agarose in PBS for scanning. A fixed volume surrounding the skull was used for 3D reconstructions. In newborn calvariae, bone volume was quantified from a fixed number of slices in the occipital lobe. The threshold was set at 280. For quantification of bone mass in the long bone, 2-month-old femurs were isolated, fixed, immobilized, and scanned. Bone parameters were quantified from 200 slices directly underneath the growth plate with the threshold set at 320 .

Mass spectrometry and metabolic tracing cOB isolated from RosaCas9 homozygous P3 pups were cultured in $6 \mathrm{~cm}$ plates and treated as indicated. Cells were incubated with $2 \mathrm{mM}\left[\mathrm{U}-{ }^{13} \mathrm{C}\right] \mathrm{glutamine}$, $2 \mathrm{mM}[\alpha-15 \mathrm{~N}]$ glutamine, $0.33 \mathrm{mM}\left[\mathrm{U}-{ }^{13} \mathrm{C}\right]$ Asparagine and $0.33 \mathrm{mM}[\alpha-15 \mathrm{~N}]$ Asparagine for either 24 or 72 hours as indicated. Cells treated for $24 \mathrm{hr}$ were washed with cold PBS and isolated three times with $-80{ }^{\circ} \mathrm{C}$ methanol on dry ice in Eppendorf tubes containing $20 \mathrm{nM}$ norvaline, which is an internal standard. The extracts were vortexed and centrifuged at 12,000 RPM for $15 \mathrm{~min}$. The supernatant was completely dried with $\mathrm{N}_{2}$ gas. The dried residue was resuspended in $25 \mu$ methoxylamine hydrochloride ( $2 \% \mathrm{MOX}$ in pyridine) and incubated for $90 \mathrm{~min}$ at $40{ }^{\circ} \mathrm{C}$ on a heat block. After the incubation, the samples were spun at maximum speed for $2 \mathrm{~min}$ and $35 \mu \mathrm{l}$ of MTBSTFA $+1 \%$ TBDMS was added followed by a 30 min incubation at $60{ }^{\circ} \mathrm{C}$. The samples were centrifuged at 12,000 RPM for 5 minutes and the supernatant was transferred to GC vials for GC-MS analysis. For the experiments 
tracing labeled amino acids into protein, cells were incubated with $2 \mathrm{mM}\left[\mathrm{U}-{ }^{13} \mathrm{C}\right]$ glutamine, $2 \mathrm{mM}$ $[\alpha-15 \mathrm{~N}]$ glutamine, $0.33 \mathrm{mM}\left[\mathrm{U}-{ }^{13} \mathrm{C}\right]$ Asparagine or $0.33 \mathrm{mM}[\alpha-15 \mathrm{~N}]$ Asparagine for 72 hours. Cells were isolated in $1 \mathrm{ml} 1 \mathrm{M} \mathrm{PCA}$ and centrifuged for $10 \mathrm{~min}$ to precipitate the protein. The precipitate was washed twice with $1 \mathrm{ml} 70 \%$ ethanol after which $20 \mathrm{nM}$ norvaline was added to the samples. The protein was hydrolyzed with $1 \mathrm{ml} 6 \mathrm{M} \mathrm{HCl}$ at $110{ }^{\circ} \mathrm{C}$ for $18 \mathrm{hr}$. The samples were cooled and $1 \mathrm{ml}$ chloroform was added and vortexed to remove hydrophobic metabolites. The isolates were centrifuged for 10 minutes and $100 \mu$ l of the supernatant was dried with $\mathrm{N}_{2}$ gas until dry, $50 \mu$ of MTBSTFA + $1 \%$ TBDMS was added followed by a 30 min incubation at $60{ }^{\circ} \mathrm{C}$. The samples were transferred to GC vials for GC-MS analysis.

\section{tRNA aminoacylation assay}

The method is adapted from two recent reports (Loayza-Puch et al., 2016). Purified RNA was resuspended in $30 \mathrm{mM} \mathrm{NaOAc/HOAc}(\mathrm{pH} 4.5)$. RNA was divided into two parts $(2 \mu \mathrm{g}$ each): one was oxidized with $50 \mathrm{mM} \mathrm{NaIO}_{4}$ in $100 \mathrm{mM} \mathrm{NaOAc} / \mathrm{HOAc}(\mathrm{pH} \mathrm{4.5)}$ and the other was treated with $50 \mathrm{mM}$ $\mathrm{NaCl}$ in $\mathrm{NaOAc} / \mathrm{HOAc}(\mathrm{pH} 4.5)$ for $15 \mathrm{~min}$ at room temperature. Samples were quenched with $100 \mathrm{mM}$ glucose for $5 \mathrm{~min}$ at room temperature, followed by desaltation using $\mathrm{G} 50$ columns and precipitation using ethanol. tRNA was then deacylated in $50 \mathrm{mM}$ Tris- $\mathrm{HCl}\left(\mathrm{pH}\right.$ 9) for $30 \mathrm{~min}$ at $37^{\circ} \mathrm{C}$, followed by another ethanol precipitation. RNA (400 ng) was then ligated the 3'adaptor.

(5'-/5rApp/TGGAATTCTCGGGTGCCAAGG/3ddC/-3') using T4 RNA ligase 2(NEB) for $4 \mathrm{hr}$ at $37{ }^{\circ} \mathrm{C} .1 \mu \mathrm{g}$ RNA was then reverse transcribed using SuperScript III first strand synthesis system with the primer (GCCTTGGCACCCGAGAATTCCA) following the manufacturer's instruction.

\section{Quantification and statistical analysis}

All statistics were performed in Graphpad six software. In cell culture studies, statistical significance was determined by an unpaired two-tailed Student's $t$-test or one-way Anova. For uCT statistical significance was determine by a paired two-tailed Student's $t$-test comparing paired littermate controls. All quantifications are represented as mean \pm standard deviation. A p value of less than 0.05 is considered statistically significant. All experiments were performed with $n \geq 3$ biological replicates. The sample size and statistical analysis are noted in the Figure legends.

\section{Acknowledgements}

The authors thank Drs. Vishal Patel and Guoli Hu for critical comments on this manuscript. This work was supported by National Institute of Health R01 grants (AR076325 and AR071967) to CMK.

\section{Additional information}

Funding

\begin{tabular}{lll} 
Funder & Grant reference number & Author \\
\hline $\begin{array}{l}\text { National Institute } \\
\text { of Arthritis and }\end{array}$ & AR076325 & Courtney M Karner \\
$\begin{array}{l}\text { Musculoskeletal and Skin } \\
\text { Diseases }\end{array}$ & \\
\hline $\begin{array}{l}\text { National Institute } \\
\text { of Arthritis and } \\
\begin{array}{l}\text { Musculoskeletal and Skin } \\
\text { Diseases }\end{array}\end{array}$ & AR071967 & Courtney M Karner \\
\hline
\end{tabular}

The funders had no role in study design, data collection and interpretation, or the decision to submit the work for publication.

Author contributions

Deepika Sharma, Yilin Yu, Leyao Shen, Guo-Fang Zhang, Investigation, Writing - review and editing; Courtney M Karner, Conceptualization, Funding acquisition, Investigation, Project administration, Writing - original draft, Writing - review and editing 
Author ORCIDs

Courtney M Karner (iD http://orcid.org/0000-0003-0387-4486

Ethics

This study was performed in accordance with the recommendations in the Guide for the Care and Use of Laboratory Animals of the National Institutes of Health. All animal procedures were approved (APN 2020-102999) by the Animal Studies Committees at Duke University and the University of Texas Southwestern Medical Center at Dallas.

Decision letter and Author response

Decision letter https://doi.org/10.7554/eLife.71595.sa1

Author response https://doi.org/10.7554/eLife.71595.sa2

\section{Additional files}

Supplementary files

- Transparent reporting form

Data availability

All data generated or analyzed during this study are included in the manuscript.

\section{References}

Adamson LF, Ingbar SH. 1967. Further studies of amino acid transport by embryonic chick bone. The Journal of Biological Chemistry 242: 2646-2652. DOI: https://doi.org/10.1016/S0021-9258(18)99619-5, PMID: 6027240

Bhutia YD, Babu E, Ramachandran S, Ganapathy V. 2015. Amino Acid transporters in cancer and their relevance to "glutamine addiction": novel targets for the design of a new class of anticancer drugs. Cancer Research 75 : 1782-1788. DOI: https://doi.org/10.1158/0008-5472.CAN-14-3745, PMID: 25855379

Birsoy K, Wang T, Chen WW, Freinkman E, Abu-Remaileh M, Sabatini DM. 2015. An Essential Role of the Mitochondrial Electron Transport Chain in Cell Proliferation Is to Enable Aspartate Synthesis. Cell 162: 540-551. DOI: https://doi.org/10.1016/j.cell.2015.07.016, PMID: 26232224

Bröer A, Brookes N, Ganapathy V, Dimmer KS, Wagner CA, Lang F, Bröer S. 1999. The astroglial ASCT2 amino acid transporter as a mediator of glutamine efflux. Journal of Neurochemistry 73: 2184-2194 PMID: 10537079.

Bröer A, Rahimi F, Bröer S. 2016. Deletion of Amino Acid Transporter ASCT2 (SLC1A5) Reveals an Essential Role for Transporters SNAT1 (SLC38A1) and SNAT2 (SLC38A2) to Sustain Glutaminolysis in Cancer Cells. The Journal of Biological Chemistry 291: 13194-13205. DOI: https://doi.org/10.1074/jbc.M115.700534, PMID: 27129276

Chen J, Tu X, Esen E, Joeng KS, Lin C, Arbeit JM, Rüegg MA, Hall MN, Ma L, Long F. 2014. WNT7B promotes bone formation in part through mTORC1. PLOS Genetics 10: e1004145. DOI: https://doi.org/10.1371/journal. pgen.1004145, PMID: 24497849

DeBerardinis R, Mancuso A, Daikhin E, Nissim I, Yudkoff M, Wehrli S, Thompson CB. 2007. Beyond aerobic glycolysis: transformed cells can engage in glutamine metabolism that exceeds the requirement for protein and nucleotide synthesis. PNAS 104: 19345-19350. DOI: https://doi.org/10.1073/pnas.0709747104, PMID: 18032601

DeBerardinis R. J, Lum JJ, Hatzivassiliou G, Thompson CB. 2008. The biology of cancer: metabolic reprogramming fuels cell growth and proliferation. Cell Metabolism 7: 11-20. DOI: https://doi.org/10.1016/j. cmet.2007.10.002, PMID: 18177721

Eagle H. 1955. Nutrition needs of mammalian cells in tissue culture. Science 122: 501-514. DOI: https://doi.org/ 10.1126/science.122.3168.501, PMID: 13255879

Elefteriou F, Benson MD, Sowa H, Starbuck M, Liu X, Ron D, Parada LF, Karsenty G. 2006. ATF4 mediation of NF1 functions in osteoblast reveals a nutritional basis for congenital skeletal dysplasiae. Cell Metabolism 4: 441-451. DOI: https://doi.org/10.1016/j.cmet.2006.10.010, PMID: 17141628

Finerman GA, Rosenberg LE. 1966. Amino acid transport in bone Evidence for separate transport systems for neutral amino and imino acids. The Journal of Biological Chemistry 241: 1487-1493 PMID: $5946610 .$,

Fitter S, Matthews MP, Martin SK, Xie J, Ooi SS, Walkley CR, Codrington JD, Ruegg MA, Hall MN, Proud CG, Gronthos S, Zannettino ACW. 2017. mTORC1 Plays an Important Role in Skeletal Development by Controlling Preosteoblast Differentiation. Molecular and Cellular Biology 37: e00668-16. DOI: https://doi.org/10.1128/ MCB.00668-16, PMID: 28069737

Flanagan B, Nichols G. 1964. Metabolic Studies of Bone in Vitro. Journal of Biological Chemistry 239: 12611265. DOI: https://doi.org/10.1016/S0021-9258(18)91421-3

Garcia-Bermudez J, Baudrier L, La K, Zhu XG, Fidelin J, Sviderskiy VO, Papagiannakopoulos T, Molina H, Snuderl M, Lewis CA, Possemato RL, Birsoy K. 2018. Aspartate is a limiting metabolite for cancer cell proliferation under hypoxia and in tumours. Nature Cell Biology 20: 775-781. DOI: https://doi.org/10.1038/ s41556-018-0118-z, PMID: 29941933 
Green CR, Wallace M, Divakaruni AS, Phillips SA, Murphy AN, Ciaraldi TP, Metallo CM. 2016. Branched-chain amino acid catabolism fuels adipocyte differentiation and lipogenesis. Nature Chemical Biology 12: 15-21. DOI: https://doi.org/10.1038/nchembio.1961, PMID: 26571352

Guntur AR, Le PT, Farber CR, Rosen CJ. 2014. Bioenergetics during calvarial osteoblast differentiation reflect strain differences in bone mass. Endocrinology 155: 1589-1595. DOl: https://doi.org/10.1210/en.2013-1974, PMID: 24437492

Hahn TJ, Downing SJ, Phang JM. 1969. sulin effect on amino acid transport in bone. Biochimica et Biophysica Acta 184: 675-677. DOI: https://doi.org/10.1016/0304-4165(69)90292-x, PMID: 5821033

Hassanein M, Hoeksema MD, Shiota M, Qian J, Harris BK, Chen H, Clark JE, Alborn WE, Eisenberg R, Massion PP. 2013. SLC1A5 mediates glutamine transport required for lung cancer cell growth and survival. Clinical Cancer Research 19: 560-570. DOI: https://doi.org/10.1158/1078-0432.CCR-12-2334, PMID: 23213057

Hosios AM, Hecht VC, Danai LV, Johnson MO, Rathmell JC, Steinhauser ML, Manalis SR, Vander Heiden MG. 2016. Amino Acids Rather than Glucose Account for the Majority of Cell Mass in Proliferating Mammalian Cells. Developmental Cell 36: 540-549. DOI: https://doi.org/10.1016/j.devcel.2016.02.012, PMID: 26954548

Hu G, Yu Y, Tang YJ, Wu C, Long F, Karner CM. 2020. The Amino Acid Sensor Eif2ak4/GCN2 Is Required for Proliferation of Osteoblast Progenitors in Mice. Journal of Bone and Mineral Research 35: 2004-2014. DOI: https://doi.org/10.1002/jbmr.4091, PMID: 32453500

Jones CL, Stevens BM, D'Alessandro A, Reisz JA, Culp-Hill R, Nemkov T, Pei S, Khan N, Adane B, Ye H, Krug A, Reinhold D, Smith C, DeGregori J, Pollyea DA, Jordan CT. 2018. Inhibition of Amino Acid Metabolism Selectively Targets Human Leukemia Stem Cells. Cancer Cell 34: 724-740. DOI: https://doi.org/10.1016/j.ccell. 2018.10.005, PMID: 30423294

Jones CL, Stevens BM, D'Alessandro A, Reisz JA, Culp-Hill R, Nemkov T, Pei S, Khan N, Adane B, Ye H, Krug A, Reinhold D, Smith C, DeGregori J, Pollyea DA, Jordan CT. 2019. Inhibition of Amino Acid Metabolism Selectively Targets Human Leukemia Stem Cells. Cancer Cell 35: 333-335. DOI: https://doi.org/10.1016/j.ccell. 2019.01.013, PMID: 30753831

Karner CM, Esen E, Okunade AL, Patterson BW, Long F. 2015. creased glutamine catabolism mediates bone anabolism in response to WNT signaling. The Journal of Clinical Investigation 125: 551-562. DOI: https://doi. org/10.1172/JCI78470, PMID: 25562323

Karner CM, Long F. 2017. Wnt signaling and cellular metabolism in osteoblasts. Cellular and Molecular Life Sciences 74: 1649-1657. DOI: https://doi.org/10.1007/s00018-016-2425-5, PMID: 27888287

Karner CM, Long F. 2018. Glucose metabolism in bone. Bone 115: 2-7. DOI: https://doi.org/10.1016/j.bone. 2017.08.008, PMID: 28843700

Kiyokawa H, Kineman RD, Manova-Todorova KO, Soares VC, Hoffman ES, Ono M, Khanam D, Hayday AC, Frohman LA, Koff A. 1996. Enhanced growth of mice lacking the cyclin-dependent kinase inhibitor function of p27(Kip1). Cell 85: 721-732. DOI: https://doi.org/10.1016/s0092-8674(00)81238-6, PMID: 8646780

Krall AS, Xu S, Graeber TG, Braas D, Christofk HR. 2016. Asparagine promotes cancer cell proliferation through use as an amino acid exchange factor. Nature Communications 7: 11457. DOI: https://doi.org/10.1038/ ncomms11457, PMID: 27126896

Kroemer G, Mariño G, Levine B. 2010. Autophagy and the integrated stress response. Molecular Cell 40: 280-293. DOI: https://doi.org/10.1016/j.molcel.2010.09.023, PMID: 20965422

Lee WC, Guntur AR, Long F, Rosen CJ. 2017. Energy Metabolism of the Osteoblast: Implications for Osteoporosis. Endocrine Reviews 38: 255-266. DOI: https://doi.org/10.1210/er.2017-00064, PMID: 28472361

Lee WC, Ji X, Nissim I, Long F. 2020. Malic Enzyme Couples Mitochondria with Aerobic Glycolysis in Osteoblasts. Cell Reports 32: 108108. DOI: https://doi.org/10.1016/j.celrep.2020.108108, PMID: 32905773

Liu Y, Zhao T, Li Z, Wang L, Yuan S, Sun L. 2018. The role of ASCT2 in cancer: A review. European Journal of Pharmacology 837: 81-87. DOI: https://doi.org/10.1016/j.ejphar.2018.07.007, PMID: 30025811

Loayza-Puch F, Rooijers K, Buil LCM, Zijlstra J, Oude Vrielink JF, Lopes R, Ugalde AP, van Breugel P, Hofland I, Wesseling J, van Tellingen O, Bex A, Agami R. 2016. Tumour-specific proline vulnerability uncovered by differential ribosome codon reading. Nature 530: 490-494. DOI: https://doi.org/10.1038/nature16982, PMID: 26878238

Nakashima K, Zhou X, Kunkel G, Zhang Z, Deng JM, Behringer RR, de Crombrugghe B. 2002. The novel zinc finger-containing transcription factor osterix is required for osteoblast differentiation and bone formation. Cell 108: 17-29. DOI: https://doi.org/10.1016/s0092-8674(01)00622-5, PMID: 11792318

Nakaya M, Xiao Y, Zhou X, Chang J-H, Chang M, Cheng X, Blonska M, Lin X, Sun S-C. 2014. flammatory T cell responses rely on amino acid transporter ASCT2 facilitation of glutamine uptake and mTORC1 kinase activation. Immunity 40: 692-705. DOI: https://doi.org/10.1016/j.immuni.2014.04.007, PMID: 24792914

Nicklin P, Bergman P, Zhang B, Triantafellow E, Wang H, Nyfeler B, Yang H, Hild M, Kung C, Wilson C, Myer VE, MacKeigan JP, Porter JA, Wang YK, Cantley LC, Finan PM, Murphy LO. 2009. Bidirectional transport of amino acids regulates mTOR and autophagy. Cell 136: 521-534. DOI: https://doi.org/10.1016/j.cell.2008.11.044, PMID: 19203585

Ornitz DM, Marie PJ. 2002. FGF signaling pathways in endochondral and intramembranous bone development and human genetic disease. Genes \& Development 16: 1446-1465. DOI: https://doi.org/10.1101/gad.990702, PMID: 12080084

Otto F, Thornell AP, Crompton T, Denzel A, Gilmour KC, Rosewell IR, Stamp GW, Beddington RS, Mundlos S, Olsen BR, Selby PB, Owen MJ. 1997. Cbfa1, a candidate gene for cleidocranial dysplasia syndrome, is essential for osteoblast differentiation and bone development. Cell 89: 765-771. DOI: https://doi.org/10.1016/ s0092-8674(00)80259-7, PMID: 9182764 
Pakos-Zebrucka K, Koryga I, Mnich K, Ljujic M, Samali A, Gorman AM. 2016. The integrated stress response. EMBO Reports 17: 1374-1395. DOI: https://doi.org/10.15252/embr.201642195, PMID: 27629041

Palm W, Thompson CB. 2017. Nutrient acquisition strategies of mammalian cells. Nature 546: 234-242. DOI: https://doi.org/10.1038/nature22379, PMID: 28593971

Pardee AB, Dubrow R, Hamlin JL, Kletzien RF. 1978. Animal cell cycle. Annual Review of Biochemistry 47: 715-750. DOI: https://doi.org/10.1146/annurev.bi.47.070178.003435, PMID: 354504

Pavlova NN, Hui S, Ghergurovich JM, Fan J, Intlekofer AM, White RM, Rabinowitz JD, Thompson CB, Zhang J. 2018. As Extracellular Glutamine Levels Decline, Asparagine Becomes an Essential Amino Acid. Cell Metabolism 27: 428-438.. DOI: https://doi.org/10.1016/j.cmet.2017.12.006, PMID: 29337136

Phang JM, Downing SJ. 1973. Amino acid transport in bone: stimulation by cyclic AMP. The American Journal of Physiology 224: 191-196. DOI: https://doi.org/10.1152/ajplegacy.1973.224.1.191, PMID: 4345737

Quarles LD, Yohay DA, Lever LW, Caton R, Wenstrup RJ. 1992. Distinct proliferative and differentiated stages of murine MC3T3-E1 cells in culture: an in vitro model of osteoblast development. Journal of Bone and Mineral Research 7: 683-692. DOI: https://doi.org/10.1002/jbmr.5650070613, PMID: 1414487

Rached M-T, Kode A, Xu L, Yoshikawa Y, Paik J-H, Depinho RA, Kousteni S. 2010. FoxO1 is a positive regulator of bone formation by favoring protein synthesis and resistance to oxidative stress in osteoblasts. Cell Metabolism 11: 147-160. DOI: https://doi.org/10.1016/j.cmet.2010.01.001, PMID: 20142102

Ren P, Yue M, Xiao D, Xiu R, Gan L, Liu H, Qing G. 2015. ATF4 and N-Myc coordinate glutamine metabolism in MYCN-amplified neuroblastoma cells through ASCT2 activation. The Journal of Pathology 235: 90-100. DOI: https://doi.org/10.1002/path.4429, PMID: 25142020

Riddle RC, Clemens TL. 2017. Bone Cell Bioenergetics and Skeletal Energy Homeostasis. Physiological Reviews 97: 667-698. DOI: https://doi.org/10.1152/physrev.00022.2016, PMID: 28202599

Rodda SJ, McMahon AP. 2006. Distinct roles for Hedgehog and canonical Wnt signaling in specification, differentiation and maintenance of osteoblast progenitors. Development 133: 3231-3244. DOI: https://doi. org/10.1242/dev.02480, PMID: 16854976

Schulte ML, Fu A, Zhao P, Li J, Geng L, Smith ST, Kondo J, Coffey RJ, Johnson MO, Rathmell JC, Sharick JT, Skala MC, Smith JA, Berlin J, Washington MK, Nickels ML, Manning HC. 2018. Pharmacological blockade of ASCT2-dependent glutamine transport leads to antitumor efficacy in preclinical models. Nature Medicine 24: 194-202. DOI: https://doi.org/10.1038/nm.4464, PMID: 29334372

Scopelliti AJ, Font J, Vandenberg RJ, Boudker O, Ryan RM. 2018. Structural characterisation reveals insights into substrate recognition by the glutamine transporter ASCT2/SLC1A5. Nature Communications 9: 38. DOI: https://doi.org/10.1038/s41467-017-02444-w, PMID: 29295993

Shen L, Sharma D, Yu Y, Long F, Karner CM. 2021. Biphasic regulation of glutamine consumption by WNT during osteoblast differentiation. Journal of Cell Science 134: jcs251645. DOI: https://doi.org/10.1242/jcs.251645, PMID: 33262314

Singha UK, Jiang Y, Yu S, Luo M, Lu Y, Zhang J, Xiao G. 2008. Rapamycin inhibits osteoblast proliferation and differentiation in MC3T3-E1 cells and primary mouse bone marrow stromal cells. Journal of Cellular Biochemistry 103: 434-446. DOI: https://doi.org/10.1002/jcb.21411, PMID: 17516572

Stegen S, Devignes C-S, Torrekens S, Van Looveren R, Carmeliet P, Carmeliet G. 2021. Glutamine Metabolism in Osteoprogenitors Is Required for Bone Mass Accrual and PTH-Induced Bone Anabolism in Male Mice. Journal of Bone and Mineral Research 36: 604-616. DOI: https://doi.org/10.1002/jbmr.4219, PMID: 33253422

Stein GS, Lian JB, Owen TA. 1990. Relationship of cell growth to the regulation of tissue-specific gene expression during osteoblast differentiation. FASEB Journal 4: 3111-3123. DOI: https://doi.org/10.1096/fasebj. 4.13.2210157, PMID: 2210157

Stein GS, Lian JB. 1993. Molecular mechanisms mediating proliferation/differentiation interrelationships during progressive development of the osteoblast phenotype. Endocrine Reviews 14: 424-442. DOI: https://doi.org/ 10.1210/edrv-14-4-424, PMID: 8223340

Sullivan LB, Gui DY, Hosios AM, Bush LN, Freinkman E, Vander Heiden MG. 2015. Supporting Aspartate Biosynthesis Is an Essential Function of Respiration in Proliferating Cells. Cell 162: 552-563. DOI: https://doi. org/10.1016/j.cell.2015.07.017, PMID: 26232225

Tonna EA, Cronkite EP. 1961. Autoradiographic studies of cell proliferation in the periosteum of intact and fractured femora of mice utilizing DNA labeling with H3-thymidine. Proceedings of the Society for Experimental Biology and Medicine. Society for Experimental Biology and Medicine 107: 719-721. DOI: https://doi.org/10.3181/00379727-107-26733, PMID: 13921864

Utsunomiya-Tate N, Endou H, Kanai Y. 1996. Cloning and functional characterization of a system ASC-like $\mathrm{Na}+-d e p e n d e n t$ neutral amino acid transporter. The Journal of Biological Chemistry 271: 14883-14890. DOI: https://doi.org/10.1074/jbc.271.25.14883, PMID: 8662767

van Geldermalsen M, Wang Q, Nagarajah R, Marshall AD, Thoeng A, Gao D, Ritchie W, Feng Y, Bailey CG, Deng N, Harvey K, Beith JM, Selinger Cl, O'Toole SA, Rasko JEJ, Holst J. 2016. ASCT2/SLC1A5 controls glutamine uptake and tumour growth in triple-negative basal-like breast cancer. Oncogene 35: 3201-3208. DOI: https://doi.org/10.1038/onc.2015.381, PMID: 26455325

Vander Heiden MG, DeBerardinis RJ. 2017. Understanding the Intersections between Metabolism and Cancer Biology. Cell 168: 657-669. DOI: https://doi.org/10.1016/j.cell.2016.12.039, PMID: 28187287

Wang J, Alexander P, Wu L, Hammer R, Cleaver O, McKnight SL. 2009. Dependence of mouse embryonic stem cells on threonine catabolism. Science 325: 435-439. DOI: https://doi.org/10.1126/science.1173288, PMID: 19589965 
Wang Q, Beaumont KA, Otte NJ, Font J, Bailey CG, van Geldermalsen M, Sharp DM, Tiffen JC, Ryan RM, Jormakka M, Haass NK, Rasko JEJ, Holst J. 2014. Targeting glutamine transport to suppress melanoma cell growth. Ternational Journal of Cancer 135: 1060-1071. DOI: https://doi.org/10.1002/ijc.28749, PMID: 24531984

Wu J, Li G, Li L, Li D, Dong Z, Jiang P. 2021. Asparagine enhances LCK signalling to potentiate CD8+ T-cell activation and anti-tumour responses. Nature Cell Biology 23: 75-86. DOI: https://doi.org/10.1038/s41556020-00615-4, PMID: 33420490

Xian L, Wu X, Pang L, Lou M, Rosen CJ, Qiu T, Crane J, Frassica F, Zhang L, Rodriguez JP. 2012. Matrix IGF-1 maintains bone mass by activation of mTOR in mesenchymal stem cells. Nature Medicine 18: 1095-1101. DOI: https://doi.org/10.1038/nm.2793, PMID: 22729283

Ye J, Kumanova M, Hart LS, Sloane K, Zhang H, De Panis DN, Bobrovnikova-Marjon E, Diehl JA, Ron D, Koumenis C. 2010. The GCN2-ATF4 pathway is critical for tumour cell survival and proliferation in response to nutrient deprivation. The EMBO Journal 29: 2082-2096. DOI: https://doi.org/10.1038/emboj.2010.81, PMID: 20473272

Yee JA. 1988. Effect of parathyroid hormone on amino acid transport by cultured neonatal mouse calvarial bone cells. Journal of Bone and Mineral Research 3: 211-218. DOl: https://doi.org/10.1002/jbmr.5650030214, PMID: 2850726

Yu Y, Newman H, Shen L, Sharma D, Hu G, Mirando AJ, Zhang H, Knudsen E, Zhang G-F, Hilton MJ, Karner CM. 2019. Glutamine Metabolism Regulates Proliferation and Lineage Allocation in Skeletal Stem Cells. Cell Metabolism 29: 966-978.. DOI: https://doi.org/10.1016/j.cmet.2019.01.016, PMID: 30773468

Zhang P, McGrath BC, Reinert J, Olsen DS, Lei L, Gill S, Wek SA, Vattem KM, Wek RC, Kimball SR, Jefferson LS, Cavener DR. 2002. The GCN2 elF2alpha kinase is required for adaptation to amino acid deprivation in mice. Molecular and Cellular Biology 22: 6681-6688. DOI: https://doi.org/10.1128/mcb.22.19.6681-6688.2002, PMID: 12215525

Zhang J, Fan J, Venneti S, Cross JR, Takagi T, Bhinder B, Djaballah H, Kanai M, Cheng EH, Judkins AR, Pawel B, Baggs J, Cherry S, Rabinowitz JD, Thompson CB. 2014. Asparagine plays a critical role in regulating cellular adaptation to glutamine depletion. Molecular Cell 56: 205-218. DOI: https://doi.org/10.1016/j.molcel.2014.08 018, PMID: 25242145 